\title{
The South Pacific Meridional Mode and Its Role in Tropical Pacific Climate Variability ${ }^{\mathscr{O}}$
}

\author{
YuJia You AND Jason C. FuRTAdo \\ School of Meteorology, University of Oklahoma, Norman, Oklahoma
}

(Manuscript received 18 December 2017, in final form 30 September 2018)

\begin{abstract}
The Pacific meridional mode, a thermodynamically coupled mode of variability, links extratropical Pacific oceanic and atmospheric anomalies to the tropical Pacific and may give rise to El Niño-Southern Oscillation (ENSO) events. While mechanistic studies on the impacts of the North Pacific meridional mode (NPMM) are prevalent in the literature, the South Pacific meridional mode (SPMM) has only recently been examined. Reanalysis and models from the archive of phase 5 of the Coupled Model Intercomparison Project (CMIP5) are used in this study to investigate further the SPMM and its role in ENSO predictability. Akin to the NPMM, the SPMM features anomalous subtropical South Pacific sea surface temperature (SST) warming in response to a weakened South Pacific subtropical high and relaxed trade winds. However, as opposed to the NPMM, the seasonality of the SPMM SST and wind components vary out of phase, in part because of the seasonal cycle of local mixed layer depth. Thus, the SPMM and the associated wind-evaporation-SST feedback are most energetic during austral summer, facilitating interaction with the concurrent NPMM conditions to regulate the occurrence, evolution, amplitude, and diversity of ENSO events. Parallel analyses with the CMIP5 models indicate that the models reasonably capture the temporal statistics and physical processes of the observed SPMM. Nonetheless, ENSO predictability within the models relies more on the slowly evolving equatorial ocean heat content than on the meridional modes. These findings reveal how the SPMM energizes components of ENSO variability, providing an additional benchmark for model evaluation of Pacific climate variability across multiple time scales.
\end{abstract}

\section{Introduction}

Tropical Pacific variability, particularly the El NiñoSouthern Oscillation (ENSO) phenomenon, is a key player used in seasonal forecasts of global weather and climate anomalies (e.g., Alexander et al. 2002; Ashok et al. 2007; Barsugli and Sardeshmukh 2002; Liu and Alexander 2007; Trenberth and Smith 2009). Because of its significant socioeconomic impacts, many studies seek to improve long-lead ENSO forecasts. However, several issues related to ENSO predictability, including the occurrence, amplitude, and spatial structure of tropical Pacific sea surface temperature (SST) anomalies (SSTA) during an event, remain challenging. Poor long-lead ENSO forecast skill exists especially during the boreal

Supplemental information related to this paper is available at the Journals Online website: https://doi.org/10.1175/JCLID-17-0860.s1.

Corresponding author: Yujia You, yujia@ldeo.columbia.edu spring prior to an event. This poor skill is referred to as the "spring predictability barrier" (e.g., Jin et al. 2008; Barnston et al. 2012; Lai et al. 2017), which likely arises because of the climatologically weak Walker cell and tropical Pacific zonal SST gradient upon which small perturbations can rapidly intensify (e.g., Kleeman and Moore 1997; Latif et al. 1994).

Searching for potential ENSO precursors, observational and modeling studies have highlighted that the North Pacific meridional mode (NPMM) operates as an effective stochastic forcing mechanism for ENSO variability (Vimont et al. 2001, 2003a,b; Chiang and Vimont 2004; Anderson 2007; Chang et al. 2007; Alexander et al. 2010). Initiated by sea level pressure (SLP) variations near the southern node (i.e., near Hawaii) of the North Pacific Oscillation (NPO; Rogers 1981; Linkin and Nigam 2008) during boreal winter and spring, the NPMM evolves via a positive feedback between the wind-induced evaporation and the underlying SSTA. This thermodynamic coupling, known as the wind-evaporationSST (WES) feedback (Xie and Philander 1994), promotes 
the southwestward propagation of the SST and wind anomalies from the north central Pacific into the western Pacific warm pool during the late boreal spring/early summer (i.e., the seasonal footprinting mechanism; e.g., Vimont et al. 2001, 2003a,b). The NPMM-induced trade wind changes also regulate the equatorial Pacific Ocean heat content [i.e., the trade wind charging (TWC) mechanism; Anderson 2007; Anderson and Perez 2015]. Unlike ENSO, the NPMM itself does not require ocean dynamics explicitly for its existence. However, NPMMtriggered equatorial oceanic Kelvin waves and the associated Bjerknes feedback are the fundamental mechanisms responsible for further ENSO development (Thomas and Vimont 2016).

Thus, the NPMM carries important implications for predicting the occurrence of ENSO events. Chang et al. (2007) indicate that more than $70 \%$ of the historical El Niño events were preceded by extreme positive NPMM episodes in the boreal spring. However, this fact implicitly means that not all extremely positive (negative) NPMM guarantee a warm (cold) ENSO event. Indeed, Larson and Kirtman $(2014,2015)$ find a large ensemble spread and little skill in ENSO forecasts using the NPMM as the sole predictor in dynamical models. A plausible explanation for these prediction failures is the antecedent and concurrent equatorial Pacific heat content and subtropical South Pacific anomalies, which may interfere constructively or destructively with the NPMM-induced tropical Pacific anomalies (e.g., Anderson 2007; Alexander et al. 2010; Su et al. 2014; Min et al. 2015; Imada et al. 2016).

While studies of the NPMM-ENSO and equatorial heat content-ENSO relationships have a long history (e.g., Zebiak and Cane 1987; Jin 1997; Meinen and McPhaden 2000; Vimont et al. 2001, 2003a,b, 2009; McPhaden 2003; Hasegawa and Hanawa 2003; Anderson 2007; Chang et al. 2007; Alexander et al. 2010; Di Lorenzo et al. 2015), ENSO precursors emanating from the South Pacific have received comparatively less attention until recently (e.g., van Loon and Shea 1985; Dayan et al. 2014; Zhang et al. 2014a,b; Ding et al. 2015a, 2017; DiNezio et al. 2017; Meehl et al. 2017; Min et al. 2017; You and Furtado 2017). Using atmosphere-slab ocean models, Zhang et al. (2014a) suggest that the South Pacific meridional mode (SPMM), represented using a SSTA index averaged over southeastern Pacific in their study, features SSTA juxtaposed with modulations in the strength of the trade wind and has a stronger expression in the equatorial Pacific than the NPMM owing to the northward displacement of the intertropical convergence zone in the eastern tropical Pacific (Zhang et al. 2014b). One concern, however, is that slab ocean models lack the necessary ocean dynamics required to properly simulate ENSO events. As such, it is difficult to disentangle the unique impacts of midlatitude internal variability (akin to the NPMM framework) from that of tropical forcing using the simple SSTA index in fully coupled model runs and observations (Zhang et al. 2014a; their Fig. 1).

Moreover, since the NPMM (SPMM) characteristic pattern features SSTA in the central (eastern) equatorial Pacific, each meridional mode may contribute differently to ENSO flavors. However, the key difference between central Pacific (CP) and eastern Pacific (EP) ENSO events is the thermocline variations associated with Kelvin wave propagation (e.g., Kao and Yu 2009; Kug et al. 2009; Capotondi et al. 2015), which can be triggered by both the NPMM- and SPMM-associated forcing. The role of the meridional modes in producing ENSO flavors is thus not completely understood. Some studies suggest that the NPMM favors CP events (Yu and Kim 2011; Vimont et al. 2014) and the SPMM favors EP events (Zhang et al. 2014a; Min et al. 2017). However, other works indicate that there is no clear evidence supporting a preference for either ENSO flavor (Ding et al. 2015b; Di Lorenzo et al. 2015) and highlight the role of equatorial heat content in the formation of EP events (Kao and Yu 2009; Kug et al. 2009; Vimont et al. 2014).

The aim of the present study is to offer potential enhancements to ENSO prediction at longer leads (e.g., their occurrence, evolution, amplitude, and flavors) by incorporating the boreal winter-spring South Pacific extratropical variability using reanalysis and fully coupled model simulations. Comparing model output with reanalysis tests further our findings and facilitates the quantification of model biases that can be used subsequently for classifying models and their fidelity in certain processes (e.g., Lin et al. 2015; Liguori and Di Lorenzo 2018). As such, this work provides an additional benchmark by which to test coupled climate models in simulating Pacific multiscale variability and build upon an emerging new paradigm on processes involved in Pacific climate variability (e.g., Clement et al. 2011; Okumura 2013; Di Lorenzo et al. 2015). Moreover, our results complement and clarify those from related studies on tropical Pacific-South Pacific interactions and relations (e.g., Ding et al. 2017; Min et al. 2017) by addressing more explicitly the importance of the South Pacific local internal atmospheric variability in the mechanics of the SPMM and presenting its important role in ENSO predictability.

The manuscript is organized as follows. Section 2 provides a description of the reanalysis datasets, model output, and the statistical methods employed in this study is provided. Then, section 3 examines the characteristics of the SPMM, investigates its linkages with the large-scale circulation variability, and details the 
different mechanisms involved with the SPMM relative to the NPMM. Evaluations of the impacts of the SPMM on ENSO events and how the SPMM interacts with the NPMM and tropical Pacific antecedent conditions are presented in section 4 . These results are also used to develop a statistical model for long-lead predictions of Pacific basin SSTA. A summary and discussion of the main results follow.

\section{Data and methods}

\section{a. Datasets}

For atmospheric variables, we examine monthlymean fields of SLP, 10-m wind, and net surface energy flux from the National Centers for Environmental Prediction (NCEP)-National Center for Atmospheric Research (NCAR) Reanalysis 1 dataset (Kalnay et al. 1996). These data cover the period 1948-2016 and have a $2.5^{\circ} \times 2.5^{\circ}$ latitude-longitude grid. SSTs over the same time period originate from the Hadley Centre Global Sea Ice and Sea Surface Temperature (HadISST) dataset (Rayner et al. 2003), which are provided on a $1^{\circ} \times 1^{\circ}$ longitude-latitude grid globally. Subsurface ocean temperatures and velocity components come from the European Centre for Medium-Range Weather Forecasts (ECMWF) Ocean Reanalysis System 4 (ORA-S4; Balmaseda et al. 2013). ORA-S4 is observationally constrained and assimilates temperature profiles with depth on 42 levels and a $1^{\circ}$ horizontal resolution. Limited by the temporal coverage of ORA-S4, the examined oceanic fields span 1958-2015. Results presented are robust when using other reanalysis products such as the National Oceanic and Atmospheric Administration (NOAA) Extended Reconstructed Sea Surface Temperature (ERSST) v3b (Smith et al. 2008), NOAACIRES Twentieth Century Reanalysis version 2c (Compo et al. 2011), ECMWF Twentieth Century Reanalysis (ERA-20C; Poli et al. 2016), ERA-Interim (Dee et al. 2011), and Simple Ocean Data Assimilation (SODA; Carton and Giese 2008). Not only do these reanalysis products employ different assimilation techniques, but they also cover different time periods, indicating that our results are also insensitive to the time period chosen for analysis.

For coupled climate model output, we select monthlymean output from 12 coupled climate models from phase 5 of the Coupled Model Intercomparison Project (CMIP5; see Table 1 for the specific models chosen; Taylor et al. 2012). Availability of the necessary atmospheric and oceanic model output dictates the selection of the models used in this study. Since we are interested in the inherent dynamics of the SPMM and its natural variability, we examine the preindustrial control
(piControl) experiment (i.e., prescribed, non-evolving greenhouse gas concentrations and aerosols mimicking conditions prior to 1850 are the primary forcings). Because of the lack of uniform availability of surface-based winds among the models, we use $1000-\mathrm{hPa}$ winds from the models as a proxy for the $10-\mathrm{m}$ wind. All oceanic and atmospheric fields from the models are regridded onto a common $1^{\circ} \times 1^{\circ}$ latitude-longitude grid to facilitate comparisons between models and for calculating multimodel ensemble (MME) means. Subsurface data are vertically interpolated onto the ORA-S4 depth coordinate.

Several climate indices are computed and analyzed in this work. The cold tongue index (CTI), defined as the average SSTA between $6^{\circ} \mathrm{S}$ and $6^{\circ} \mathrm{N}$ and between $180^{\circ}$ and $90^{\circ} \mathrm{W}$, represents SSTA variability over the tropical Pacific strip (e.g., Deser and Wallace 1990). Note that the CTI only explains a portion of the signal associated with ENSO, with the remaining portion of the signal captured by an east-west tropical SSTA dipole (e.g., Capotondi et al. 2015). With the ORA-S4, the $20^{\circ} \mathrm{C}$ isotherm $Z_{20}$ is calculated through vertical interpolation of the subsurface temperature field. As a proxy for tropical ocean heat content, the warm water volume (WWV) is defined as the average depth of $Z_{20}$ over $5^{\circ} \mathrm{S}-$ $5^{\circ} \mathrm{N}, 120^{\circ} \mathrm{E}-80^{\circ} \mathrm{W}$ (e.g., Meinen and McPhaden 2000).

\section{b. Methods}

All data are linearly detrended before conducting analyses. Monthly-mean anomalies are defined as deviations from the corresponding mean annual cycle in the specific dataset. A 3-month running mean is applied to all fields prior to analysis. To compare model statistics with reanalysis, we subdivide the output of each CMIP5 model into 70-yr segments and then compute the statistics and quantities on those 70-yr segments. The model mean is then computed as the average of the statistics among the several subintervals. Finally, the MME mean is computed by averaging a particular statistic over all of the models, with uncertainty denoted by the unit standard deviation among the models.

Several statistical methods are used in this study. Empirical orthogonal functions (EOFs) and maximum covariance analysis (MCA; Bretherton et al. 1992) are employed to study the variability and covariability of atmospheric and oceanic fields, respectively. Power spectral and cross-spectral analyses are used to examine the frequency of the meridional modes and their relationship to tropical Pacific variability. Prior to spectral decomposition, the time series are tapered by $10 \%$ using a 25 -yr overlapping Hanning window. This technique increases the degrees of freedom fivefold for significance testing in observations. For the models, the degrees of freedom are multiplied by the number of 
TABLE 1. The coupled climate models from CMIP5 analyzed in this study, along with total length of the piControl run for each model (yr).

\begin{tabular}{|c|c|c|}
\hline Institution, country & Model acronym & Length of piControl run (yr) \\
\hline National Center for Atmospheric Research (NCAR), United States & CCSM4 & 501 \\
\hline $\begin{array}{l}\text { Canadian Centre for Climate Modeling and Analysis (CCCma), } \\
\text { Canada }\end{array}$ & CanESM2 & 296 \\
\hline $\begin{array}{l}\text { Centre National de Recherches Météorologiques/Centre Européen } \\
\text { de Recherche et Formation Avancées en Calcul Scientifique } \\
\text { (CNRM-CERFACS), France }\end{array}$ & CNRM-CM5 & 850 \\
\hline $\begin{array}{l}\text { Commonwealth Scientific and Industrial Research Organization } \\
\text { (CSIRO) in collaboration with the Queensland Climate Change } \\
\text { Centre of Excellence (QCCCE), Australia }\end{array}$ & CSIRO-Mk3.6.0 & 500 \\
\hline Geophysical Fluid Dynamics Laboratory, United States & GFDL-ESM2G & 500 \\
\hline $\begin{array}{l}\text { National Aeronautics and Space Administration (NASA) Goddard } \\
\text { Institute for Space Studies (GISS), United States of America }\end{array}$ & GISS-E2-R & 250 \\
\hline Met Office Hadley Centre, England & HadGEM2-CC & 240 \\
\hline Institute for Numerical Mathematics, Russia & INMCM4 & 500 \\
\hline $\begin{array}{l}\text { Atmosphere and Ocean Research Institute (The University of Tokyo)/ } \\
\text { National Institute for Environmental Studies/Japan Agency for } \\
\text { Marine-Earth Science and Technology, Japan }\end{array}$ & MIROC5 & 300 \\
\hline Institut Pierre-Simon Laplace, French & IPSL-CM5A-MR & 300 \\
\hline Max Planck Institute for Meteorology (MPI-M), Germany & MPI-ESM-P & 550 \\
\hline Norwegian Climate Centre (NCC), Norway & NorESM1-ME & 252 \\
\hline
\end{tabular}

70 -yr subintervals for that particular model. Significance $(p<0.05)$ in these spectra is assessed using the $F$ statistic, following Torrence and Compo (1998). For presentation, power spectra are normalized such that values represent the percent of variance explained at a particular period.

Correlation and regression are also used in this study. For observations, significance testing for the temporal correlation and regression is done through a two-sided Student's $t$ test with an effective degrees of freedom $N^{*}$ computed as in Bretherton et al. (1999),

$$
N^{*}=N \frac{1-r_{1} r_{2}}{1+r_{1} r_{2}}
$$

where $N$ is the total sample size, and $r_{1}$ and $r_{2}$ are the lag- 1 autocorrelations of the index and field used in the analysis, respectively. For the models, significance for the regression maps is defined when at least 9 out of 12 models have the same sign as the ensemble mean.

Lag correlation is commonly used to identify potential precursors of a given variable (e.g., $y$ correlates with $x_{1}$ at a certain time lag). However, other climate processes (e.g., a process $x_{2}$ ) may intervene with $x_{1}$ to augment/ offset its relationship with $y$. For this purpose, we consider the variation of the correlation between $x_{1}$ and $y$ conditioned on $x_{1}$ and $x_{2}$ : i.e., corr_diff $\left(x_{2}\right)=\operatorname{corr}\left(x_{1}\right.$, $\left.y \mid x_{1} \times x_{2}>0\right)-\operatorname{corr}\left(x_{1}, y \mid x_{1} \times x_{2}<0\right)$. Whether $x_{2}$ significantly modulates the correlation of $x_{1}$ with $y$ is evaluated through a Monte Carlo resampling technique. For the Monte Carlo testing, we generate 10000 normally distributed synthetic time series $x_{P}$ with identical length, mean, and variance as $x_{2}$ and calculate the probability density function (PDF) of corr_diff $\left(x_{P}\right)$. The significance is then represented by the probability that corr_diff $\left(x_{2}\right)>$ corr_diff $\left(x_{P}\right)$. For the models, which have a much larger sample size, we generate 70-yr-long $x_{1}, x_{2}, y$, and $x_{P}$ time series randomly to produce PDFs of corr_diff $\left(x_{2}\right)$ and corr_diff $\left(x_{P}\right)$, respectively. A two-tailed KolmogorovSmirnov goodness-of-fit test is applied to compare the two PDFs and test if they are significantly different from each other.

\section{Characteristics of the SPMM}

\section{a. Reanalysis}

\section{1) SPATiotemporal STRUCtURE OF THE SPMM}

In this study, we define the SPMM in reanalysis following the methodology of Chiang and Vimont (2004) for meridional modes - that is, the leading MCA mode (MCA-1) of the cross-covariance matrix between SST and $10-\mathrm{m}$ wind anomalies in the subtropical South Pacific $\left(35^{\circ}-10^{\circ} \mathrm{S}, 180^{\circ}-70^{\circ} \mathrm{W}\right)$. Note that our domain excludes the tropical Pacific to highlight the extratropical processes associated with the SPMM. Furthermore, as ENSO teleconnections are seasonally dependent, we linearly remove the contemporaneous CTI from the fields month by month prior to MCA to isolate the local internal variability. Figure 1 summarizes the spatiotemporal features of the SPMM. The SPMM accounts for $54.1 \%$ of the total coupled variance and is distinguished 


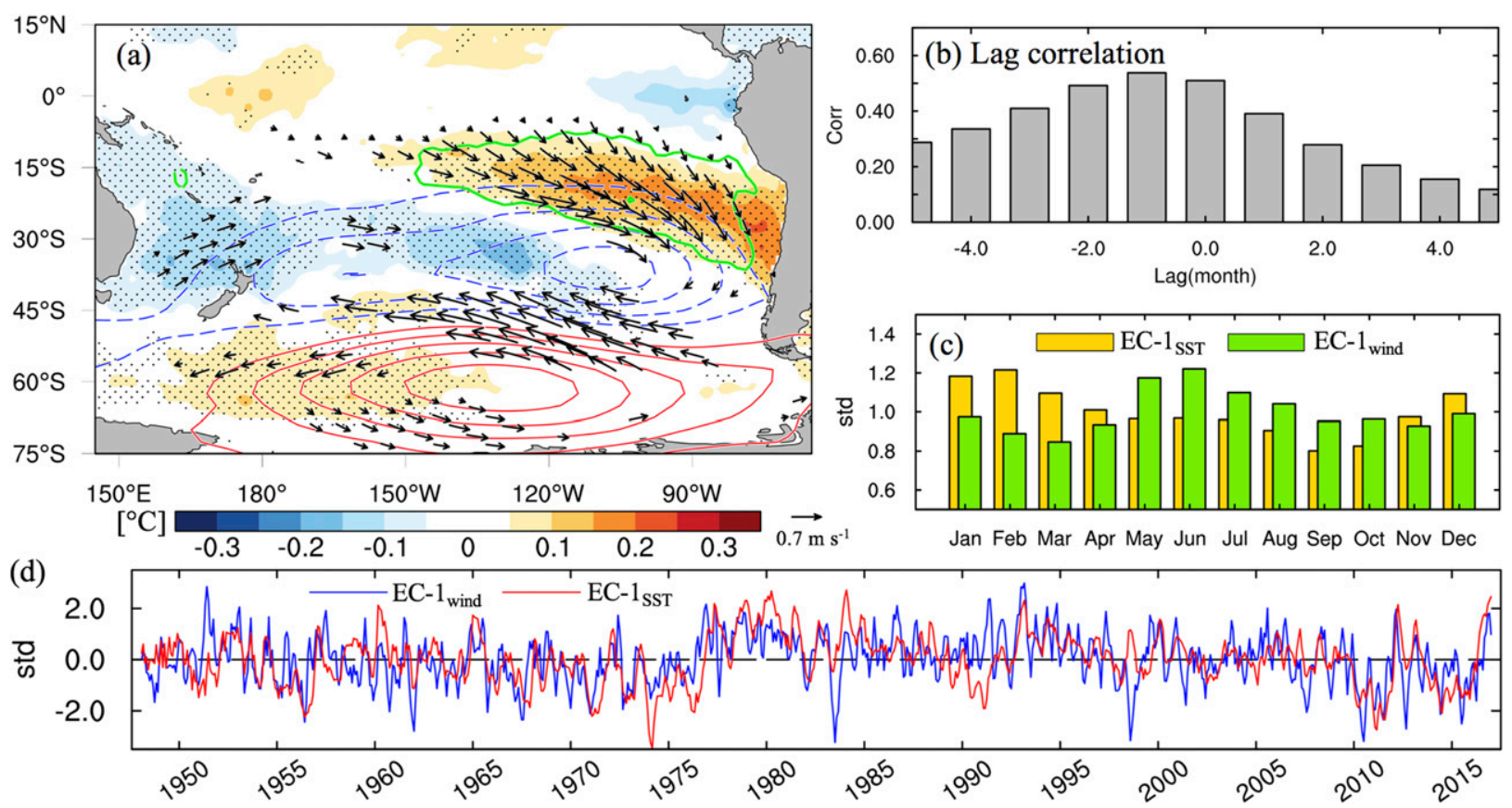

FIG. 1. (a) Regression of observed monthly-mean SSTA (shading; ${ }^{\circ} \mathrm{C}$ ), SLPA (blue/red contours; hPa), 10-m wind anomalies (vectors; $\mathrm{m} \mathrm{s}^{-1}$ ), and net surface latent heat flux (green contours; $\mathrm{W} \mathrm{m}^{-2}$ ) onto the standardized monthly-mean EC-1 $1_{\text {wind }}$ index (i.e., the SPMM index). The contour interval is $0.4 \mathrm{hPa}$ for SLPA and $5 \mathrm{~W} \mathrm{~m}^{-2}$ for latent heat flux. The reference wind vector is $0.7 \mathrm{~m} \mathrm{~s}{ }^{-1}$. Positive (negative) values are represented by solid (dashed) contours; zero contour omitted. Positive (negative) latent heat flux anomalies indicate anomalous heat flux into (out of) the ocean. Stippled areas indicate significance of SSTA at the 95\% level according to a two-tailed Student's $t$ test. Only significant wind vectors are drawn. (b) Lag correlation between the EC-1 $1_{\text {wind }}$ and EC- $1_{\text {SST }}$ indices. Negative (positive) lags indicate that the EC- $1_{\text {wind }}$ index leads (lags) the EC- $1_{\mathrm{SST}}$ index. (c) Seasonality of the EC- $1_{\text {wind }}$ (green bars) and EC- $1_{\mathrm{SST}}$ (yellow bars) indices (i.e., the standard deviation of the index as a function of calendar month). (d) The standardized EC-1 $1_{\text {wind }}$ (blue line) and $\mathrm{EC}-1_{\mathrm{SST}}$ (red line) indices as a function of time.

significantly from higher modes based on a Monte Carlo test. In the positive phase, a northeast-southwest-oriented SLP anomaly (SLPA) dipole exists between the subtropical and higher latitudes with a nodal point near $50^{\circ} \mathrm{S}$ (Fig. 1a). The northern pole of the SLPA dipole modulates the strength of the South Pacific subtropical high and therefore the climatological southeasterly trade winds, generating anomalous latent heat fluxes into the underlying ocean (Fig. 1a, green contours). Associated with the wind and latent heat flux anomalies, an SSTA dipole forms in the subtropical South Pacific and extends into the central-eastern equatorial Pacific. The lag correlation between the atmospheric and oceanic components of the SPMM peaks when the wind expansion coefficient time series $\left(\mathrm{EC}-1_{\text {wind }}\right)$ leads the SST expansion coefficient time series $\left(\mathrm{EC}-1_{\mathrm{SST}}\right)$ by one month ( $r=0.54 ; p<0.05$; Fig. 1b), suggesting that the atmosphere drives the ocean. Intriguingly, contrary to the NPMM (Chiang and Vimont 2004), the seasonality of the EC- $1_{\text {wind }}$ and $\mathrm{EC}-1_{\mathrm{SST}}$ indices evolves out of phase; that is, the SST variance maximizes during austral summer while the wind variance peaks during austral winter (Fig. 1c).
The SPMM possesses variability ranging from seasonal to interannual and longer time scales (Fig. 1d), indicating that this mode may contribute to Pacific climate variability across multiple time scales. Further comments on this multiscale variability are reserved for section 5. Following previous studies on the NPMM (e.g., Vimont et al. 2003a,b; Chiang and Vimont 2004; Chang et al. 2007), we use the EC- $1_{\text {wind }}$ time series to define the SPMM in the remainder of this paper. Moreover, the anomalous wind field associated with the SPMM contains information about atmospheric intrinsic variability and feedback from the underlying ocean, and is closely related to the generation of oceanic Kelvin waves (Thomas and Vimont 2016). Conversely, the SSTA field may be affected by ENSO nonlinearity (Chiang and Vimont 2004). Note that changes in the analysis technique (e.g., computing the SPMM by removing the first two leading principal components (PCs) of the tropical Pacific SSTA before performing MCA and reasonable changes in domain size) yield similar results (not shown).

Next, we examine EOFs of the atmospheric and oceanic fields separately to quantify further the significance of the 
(a) SLP-1

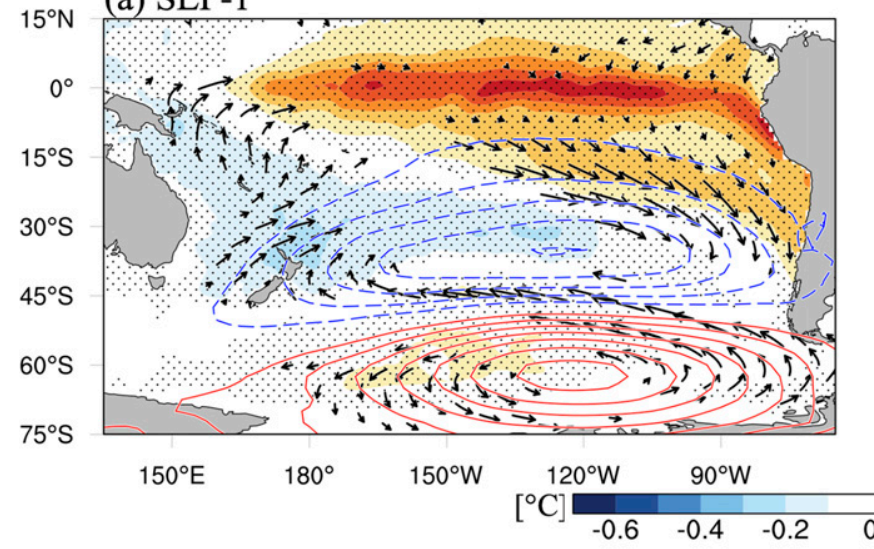

(b) SST-1

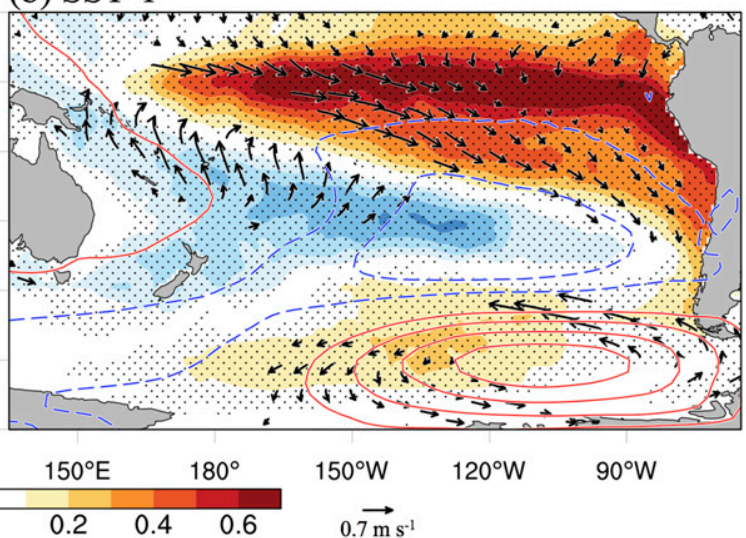

(d) $\mathrm{SST}_{\mathrm{res}}-1$

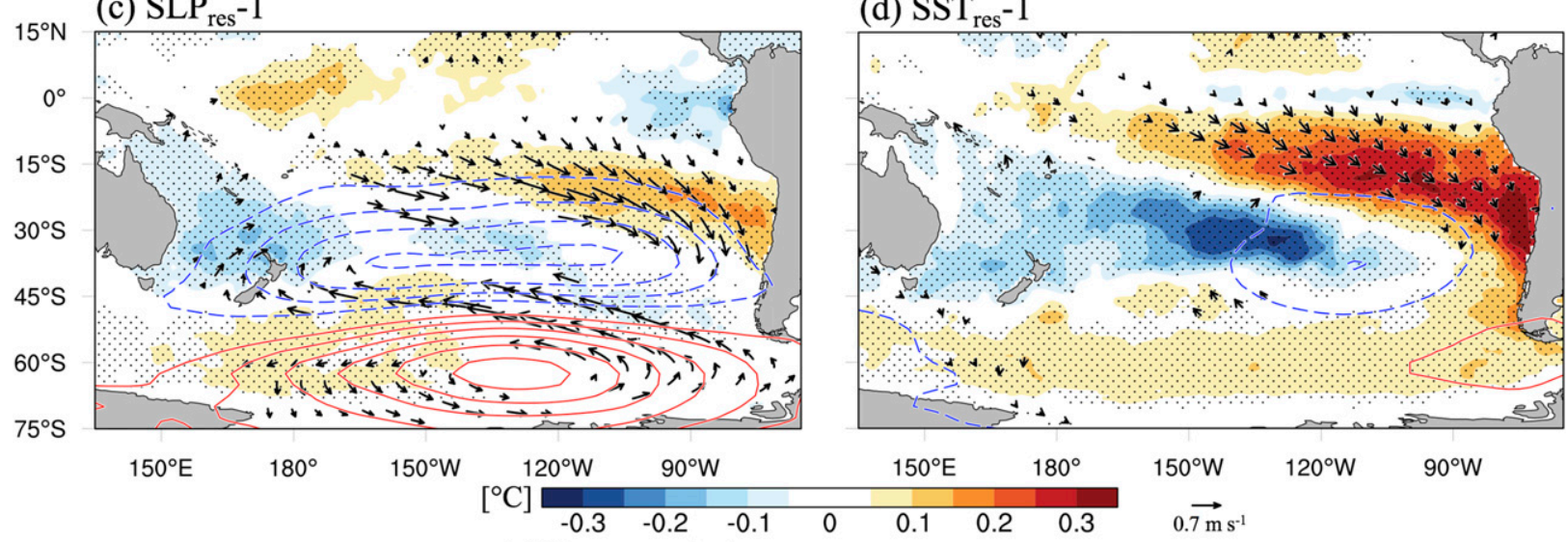

(e) Lag correlation

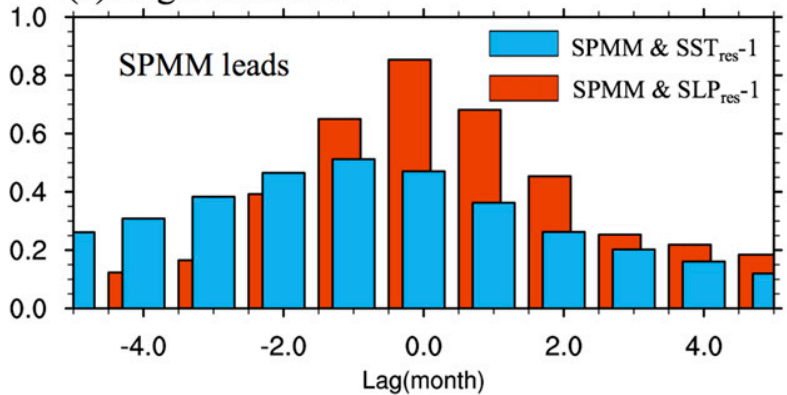

FIG. 2. Regression of monthly-mean SSTA (shading; ${ }^{\circ} \mathrm{C}$ ), SLPA (blue/red contours; hPa), and 10-m wind anomalies (vectors; $\mathrm{m} \mathrm{s}^{-1}$ ) onto the standardized (a) SLP-1, (b) SST-1, (c) SLP res $^{-1}$, and (d) SST $_{\text {res }}-1$ indices (see text for details). The contour interval is $0.4 \mathrm{hPa}$. The reference wind vector is $0.7 \mathrm{~m} \mathrm{~s}^{-1}$. Positive (negative) values represented by solid (dashed) contours; zero contour omitted. Only significant $(p<0.05)$ wind vectors are plotted. Stippling is the same as in Fig. 1a. (e) Lag correlation between the SPMM and SST res -1 indices (blue) and the SPMM and SLP res $^{-1}$ indices (red). Negative (positive) lags indicate the SPMM index leads (lags) the other index.

atmosphere-ocean interaction involved with the SPMM (Fig. 2). The leading SLP (SLP-1) and SST (SST-1) modes capture $49.3 \%$ and $41.5 \%$ of the total variance, respectively, and are significantly distinguished from higher-order modes per the North et al. (1982) criteria. Akin to the NPO, the SLP-1 features a north-south dipole (Fig. 2a) similar to that in Fig. 1a. A similar dipolar structure emerges (albeit weaker) in the SLPA field associated with the SST-1 (Fig. 2b). Although both SLP-1 and SST-1 are significantly correlated with the tropical Pacific SSTA, the two singlefield EOF spatial maps also share similarities with the SLPA and SSTA fields associated with the SPMM outside of the tropical strip (Fig. 1a).

To investigate further South Pacific internal climate variability, we repeat the above EOF analysis, but this time the CTI is linearly removed from the fields prior to eigenanalysis. The leading residual SLPA ( $\mathrm{SLP}_{\text {res }}-1$; Fig. 2c) and SSTA (SST res -1 ; Fig. 2d) modes account for 
$46.0 \%$ and $25.5 \%$ of the residual variance, respectively, and are significantly separated from higher-order modes per the North et al. (1982) significance test. The similarities between the SLP-1 (SST-1) and SLP ${ }_{\text {res }}-1\left(\mathrm{SST}_{\text {res }}-1\right)$ modes in both the SLPA and SSTA fields outside of the tropical Pacific indicate that the tropically forced and local components of the South Pacific variability project onto an overall similar pattern. Differences between the subtropical SLPA, low-level wind anomalies, and SSTA patterns in the residual EOF regression fields (Figs. 2c,d) and those associated with the SPMM (Fig. 1a) are small. The lag correlation between the EC- $1_{\text {wind }}$ and the $\mathrm{SLP}_{\text {res }}-1\left(\mathrm{SST}_{\text {res }}-1\right)$ indices peaks at lag-0 $(+1)$ month $[r=0.92(0.54)$; Fig. 2e]. Since EOF analysis is applied to a single field and MCA is applied to the covariance matrix of two fields, this strong resemblance and covariance between individual EOF and MCA modes highlights the significance of the airsea coupling involved with the SPMM, with the largescale SLPA dipole a likely contributor to SPMM dynamics.

\section{2) SeAsonality of THE SPMM}

The spatiotemporal characteristics of the observed SPMM align well with the NPMM except that the seasonality of the EC- $1_{\text {wind }}$ and EC- $1_{\text {SST }}$ indices varies out of phase (Fig. 1c). To examine the physical process responsible for this behavior, the seasonal cycle of the SPMM air-sea coupling strength is investigated by computing the correlation between the EC- $1_{\text {wind }}$ and EC- $1_{\text {SST }}$ time series separately for each calendar month (Fig. 3a). Although the MCA is designed to extract coupled modes of variability, the coupling strength undergoes a substantial seasonal cycle. Specifically, the coupling peaks in austral summer $(r \approx 0.7)$ and is relatively weak during austral winter $(r \approx 0.4)$ despite wind anomalies being largest (and more variable) during austral winter (Fig. 1d; green bars). As such, factors other than the windinduced latent heat fluxes must be considered in shaping the SPMM SSTA field.

To explore further the seasonality of the SPMM, the spatial structures of the positive phase of the SPMM during austral summer [December-February (DJF)] and winter [June-August (JJA)] are displayed in Figs. $3 \mathrm{~b}$ and $3 \mathrm{~d}$, respectively. During both seasons, the anomalously weak southeasterly trade winds result in anomalous latent heat fluxes entering the ocean. Although the latent heat flux anomalies are generally stronger in magnitude during JJA (Fig. 3d) than during DJF (Fig. 3b), the JJA SSTA response is weak over the eastern subtropical South Pacific (Fig. 3d). This discrepancy in the SSTA signature may exist, however, because of subsurface processes. By examining the average subsurface temperatures over the SPMM loading center (i.e., red box in Figs. 3b,d), the deeper (shallower) mixed layer during JJA (DJF) appears to reduce (increase) the SSTA sensitivity to surface heat flux anomalies (Figs. 3c,e). Therefore, we hypothesize that the seasonal cycle of the mixed layer depth (MLD) may dictate why the maximum SPMM amplitude occurs during austral summer rather than winter.

To quantitatively evaluate the effect of the MLD seasonal cycle on the SPMM, we consider the heat budget equation for the mixed layer in the region denoted by the red box in Figs. 3b and 3d:

$$
\begin{aligned}
\rho_{0} c_{p} \int_{0}^{\mathrm{MLD}} \frac{\partial T}{\partial t} d z=Q_{\text {net }}+Q_{\mathrm{ocn}}=Q_{\text {total }} \\
Q_{\text {net }}=Q_{\text {latent_heat }}+Q_{\text {sensible_heat }}+Q_{\text {longwave_radiation }} \\
\quad+Q_{\text {shortwave_radiation }}, \quad \text { and } \\
Q_{\text {ocn }}=-\rho_{0} c_{p} \int_{0}^{\mathrm{MLD}}\left(u \frac{\partial T}{\partial x}+v \frac{\partial T}{\partial y}+w \frac{\partial T}{\partial z}\right) d z
\end{aligned}
$$

where $\rho_{0}=1020 \mathrm{~kg} \mathrm{~m}^{-3}$ is the density of seawater, $c_{p}=$ $3900 \mathrm{~J} \mathrm{~kg}^{-1} \mathrm{~K}^{-1}$ is the specific heat capacity of seawater, $\partial T / \partial t$ is the time tendency of the mixed layer temperature, $Q_{\text {net }}$ is the net (radiative and nonradiative) atmospheric heat flux, and $Q_{\text {ocn }}$ is the convergence of ocean heat transport. Here, the MLD is defined as the depth where the ocean temperature is $0.5^{\circ} \mathrm{C}$ less than the climatological SST (e.g., Kara et al. 2003). Additionally, the growth rate of the SPMM-related SSTA is determined by linearly regressing select variables in the heat budget equation onto the normalized monthlymean SPMM index for each month. The contribution of various terms in (3) to $Q_{\text {net }}$ (Figs. 4a,b) highlights the dominance of the latent heat flux, which peaks during JJA when the surface wind anomalies are large in magnitude (Fig. 4d). The contribution of $Q_{\text {ocn }}$ is weak throughout the year (Fig. 4a), inserting negligible influences on the growth of the SPMM. The SSTA increase slowly (rapidly) (Fig. 4c) during the cold (warm) season when the MLD is deeper (shallower). Therefore, the South Pacific MLD likely plays an essential role in regulating the effectiveness of the air-sea coupling processes and the WES feedback associated with the SPMM. This result supports a similar argument proposed by Zhang et al. (2014a).

The apparent seasonal cycle of the air-sea coupling strength in the SPMM differs from that in the NPMM, in which the SSTA and wind components vary in phase and peak in the late boreal winter and spring (e.g., Chiang 


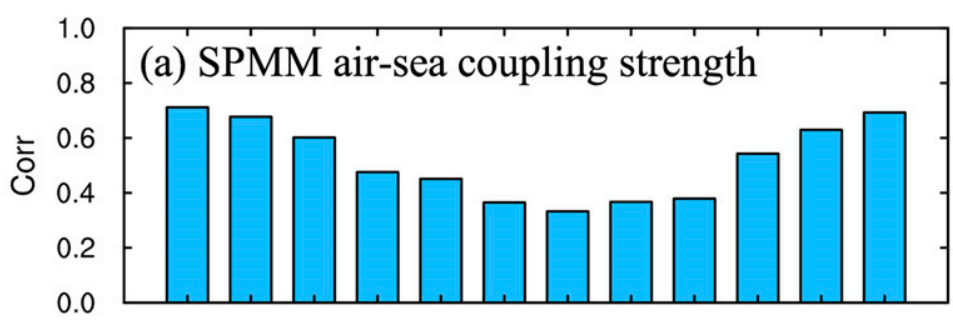

Jan Feb Mar Apr May Jun Jul Aug Sep Oct Nov Dec

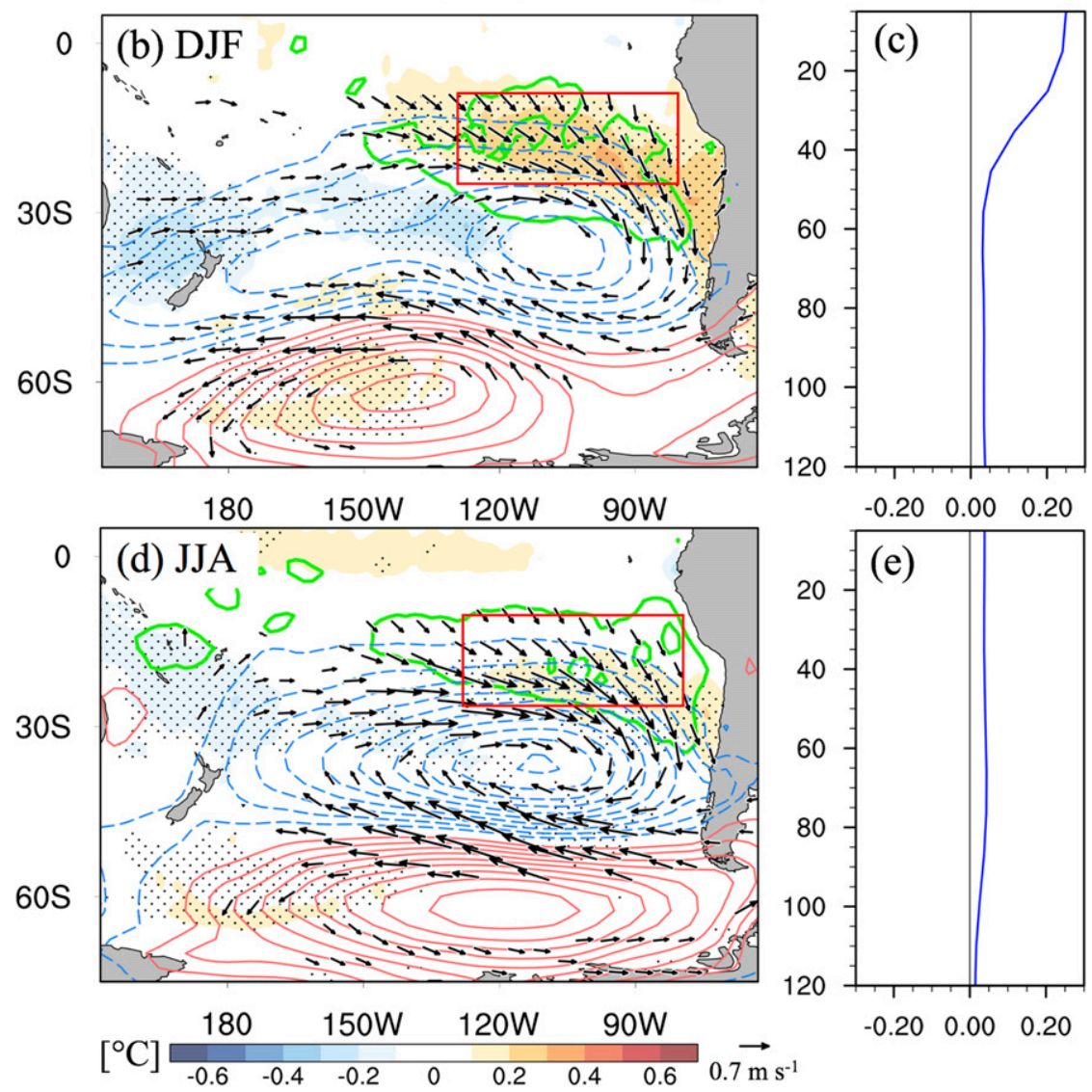

FIG. 3. (a) Month-to-month correlation between the EC-1 wind $_{\text {and EC- }} 1_{\mathrm{SST}}$ indices from reanalysis (i.e., a measure of the air-sea coupling strength of the SPMM). (b) As in Fig. 1a, except for DJF. The line contour interval is $0.4 \mathrm{hPa}$ (blue/red contours) and $5 \mathrm{~W} \mathrm{~m}^{-2}$ (green contours). The reference wind vector is $0.7 \mathrm{~m} \mathrm{~s}^{-1}$. (c) Regression of DJF ocean potential temperature anomalies $\left({ }^{\circ} \mathrm{C}\right)$ as a function of depth averaged over $10^{\circ}-25^{\circ} \mathrm{S}, 130^{\circ}-$ $80^{\circ} \mathrm{W}$ [red box in (b) and (d)] onto the SPMM index. (d) As in (b), but for JJA. (e) As in (c), but for JJA.

and Vimont 2004). Although the MLD and surface wind experience similar seasonality in the region affected by the NPMM, the amplitude of the mean seasonal cycle in the Northern Hemisphere is greater compared to the Southern Hemisphere because of the stronger continental effects on the meridional temperature gradient (e.g., Kiladis and Mo 1999; Cai and Watterson 2002). Hence, in contrast to the SPMM, the NPMM is predominantly controlled by atmospheric processes rather than the seasonal cycle of the MLD (Vimont et al. 2009).

\section{b. CMIP5 models}

Given the close relationship between the SPMM and ENSO, we suggest that coupled climate models should have a reasonable SPMM simulation in order to capture realistic ENSO behavior. Hence, we next examine how well 12 models in the CMIP5 model archive replicate the 

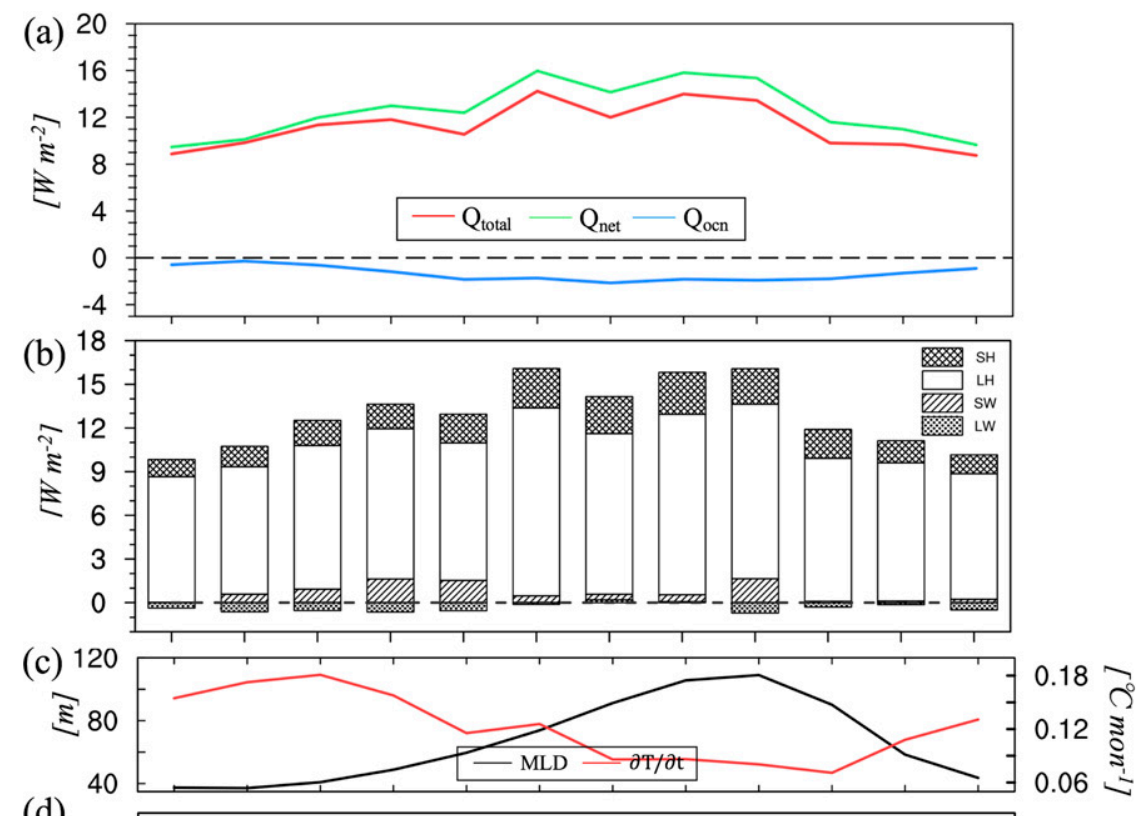

(d)

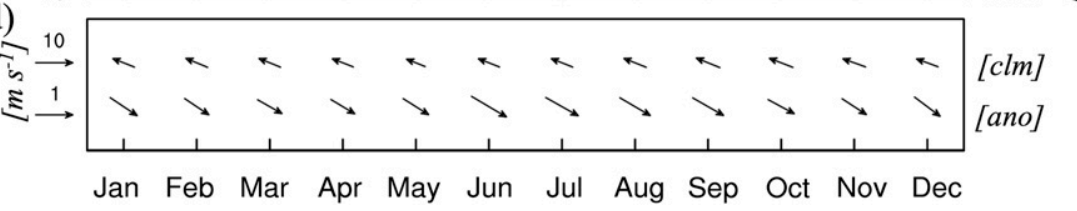

FIG. 4. (a) Month-to-month regression of net atmospheric heat flux $Q_{\text {net }}$ (positive values indicate fluxes into the ocean; green line; $\mathrm{W} \mathrm{m}^{-2}$ ), convergence of ocean heat transport $Q_{\text {ocn }}$ (positive values indicate convergence; blue line; $\mathrm{W} \mathrm{m}^{-2}$ ), and total heat flux $Q_{\text {total }}$ (red line; $\mathrm{W} \mathrm{m}^{-2}$ ) onto the SPMM index. (b) The individual components of the net atmospheric heat flux $\left(\mathrm{W} \mathrm{m}^{-2}\right)$ regression term as a function of month: sensible heat flux $(\mathrm{SH})$, latent heat flux $(\mathrm{LH})$, shortwave radiation flux (SW), and longwave radiation flux (LW). (c) Climatological mixed layer depth (MLD; black line; $\mathrm{m}$ ) and vertically averaged temperature tendency $\partial T / \partial t$ (red line; ${ }^{\circ} \mathrm{C}$ month ${ }^{-1}$ ), calculated from Eqs. (2)-(4). (d) Climatological and anomalous 10-m winds, shown at top and bottom respectively (vectors; $\mathrm{m} \mathrm{s}^{-1}$ ). Note the different reference vectors given for the climatological and anomalous winds. All terms in (a)-(d) are averaged over $10^{\circ}-$ $25^{\circ} \mathrm{S}, 130^{\circ}-80^{\circ} \mathrm{W}$ (i.e., red box in Fig. $3 \mathrm{~b}$ ).

observed SPMM features. Because of the lack of observations in the South Pacific before the satellite era, the additional output from hundreds of years of model simulations would test the fidelity of our findings using the relatively short reanalysis period (Furtado et al. 2011). When applying the same MCA procedure for extracting the SPMM in reanalysis to model outputs, several CMIP5 models produce erroneous and unfamiliar patterns (e.g., CCSM4, CSIROMk-3.6.0, NorESM1-ME; see Fig. S1 in the online supplemental material). To circumvent this problem, we adopt a different approach to elucidate the mechanics and characteristics of the SPMM in the CMIP5 models. Instead of conducting MCA on the model fields, the anomaly fields of each model (after linearly removing the CTI from the fields) are projected onto the observed SPMM pattern (i.e., Fig. 1a). Hence, the SPMM index in each of the models (i.e., the time series obtained by projecting the anomalous low-level wind field from the models onto the SPMM characteristic wind pattern from reanalysis) represents low-level wind variability with respect to the same observation-based SPMM. As such, our evaluation of the models will focus on the ability of the models to replicate observed temporal statistics and the physical processes associated with the SPMM rather than their ability to simulate the characteristic SPMM pattern.

Figure 5a presents the MME mean SPMM pattern obtained by averaging the individual regression maps of the various fields onto the SPMM index for each model. As expected from our methodology, the spatial pattern of the MME mean SPMM bears a strong resemblance to that from reanalysis (Fig. 1a), and the SPMM-like pattern emerges in the residual EOFs of the SLPA and SSTA fields (Figs. 5d,e). Temporal statistics of the simulated SPMM also follow those from reanalysis, particularly the out-of-phase seasonality between the wind and SST fields (Figs. 5b,c). As such, the strongest (weakest) air-sea coupling in the MME occurs during DJF (JJA) 

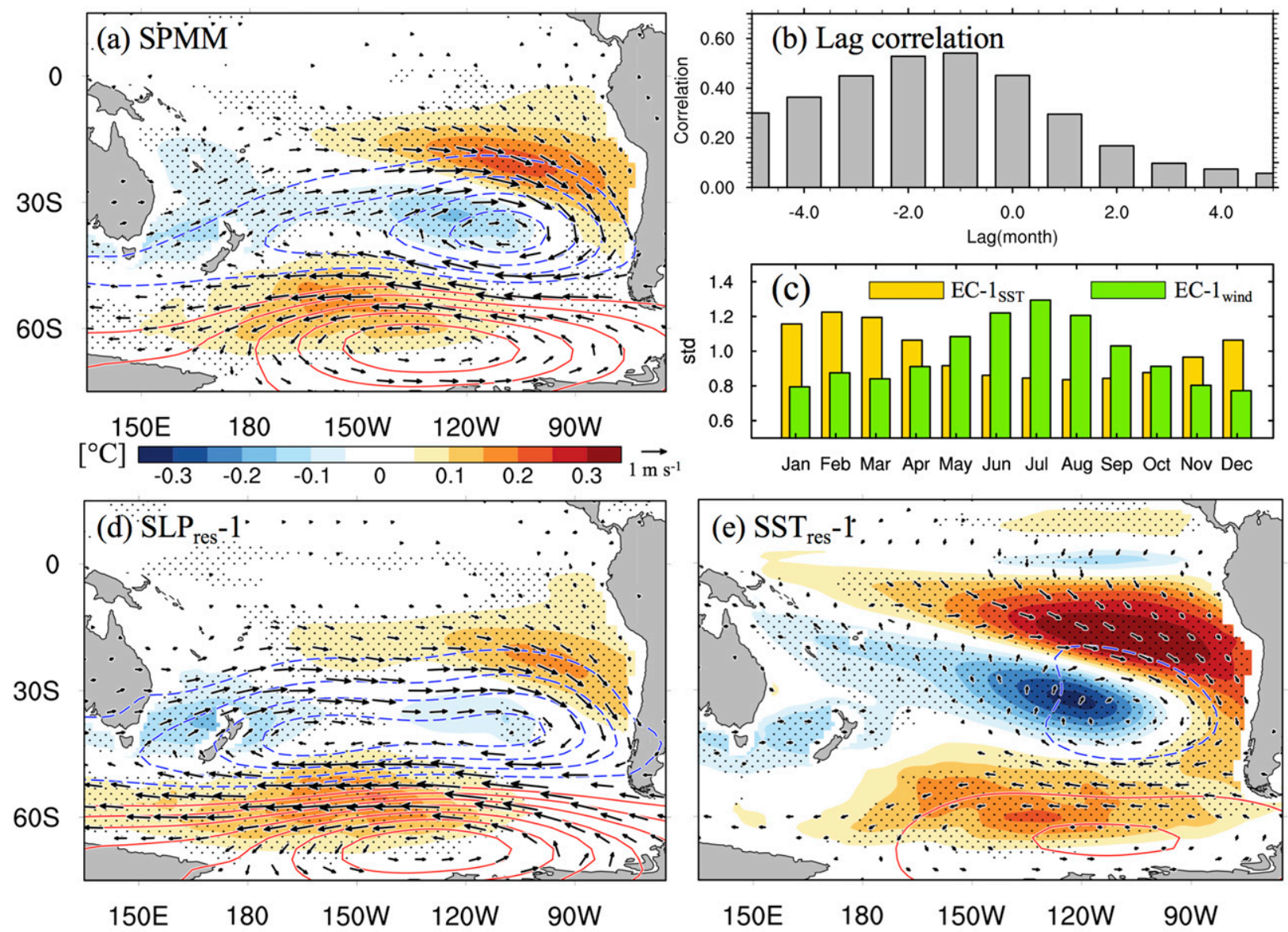

(f) Lag correlation

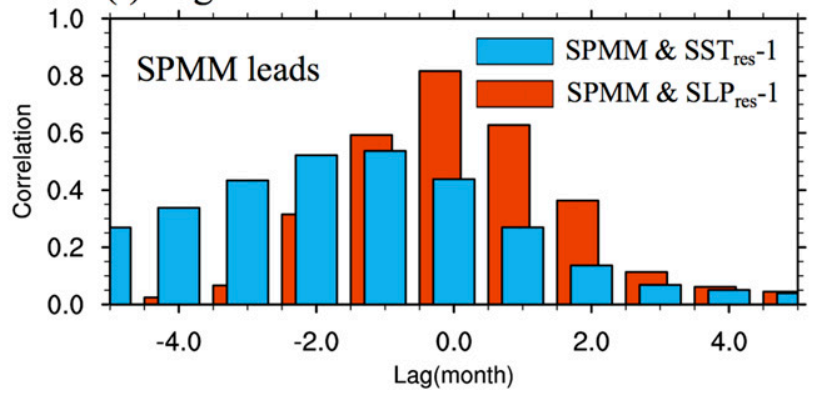

FIG. 5. (a) MME-mean regression of observed monthly-mean SSTA (shading; ${ }^{\circ} \mathrm{C}$ ), SLPA (blue/red contours; hPa), and 10-m wind anomalies (vectors; $\mathrm{m} \mathrm{s}^{-1}$ ) onto the standardized monthly-mean EC- $1_{\text {wind }}$ index (i.e., the SPMM index), as computed for the CMIP5 models (see text). The contour interval is $0.4 \mathrm{hPa}$ for SLPA. The reference wind vector is $1 \mathrm{~m} \mathrm{~s}^{-1}$. Positive (negative) values represented by solid (dashed) contours; zero contour omitted. Stippling denotes statistical significance of SSTA (i.e., at least 9 out of 12 model have the same sign of the anomaly). Only statistically significant wind vectors are shown. (b),(c) As in Figs. 1b,c but for the CMIP5 MME. (d) MME regression of monthly-mean SSTA (shading; ${ }^{\circ} \mathrm{C}$ ), SLPA (blue/red contours; $\mathrm{hPa}$ ), and $10-\mathrm{m}$ wind anomalies (vectors; $\mathrm{m} \mathrm{s}^{-1}$ ) onto the standardized $\mathrm{SLP}_{\text {res }}-1$ index from the CMIP5 models. Contours, vectors, and stippling as in (a). (e) As in (d), but for the $\mathrm{SST}_{\text {res }}{ }^{-1}$ index. (f) As in Fig. 2f, but for the CMIP5 MME.

(Fig. 6a) regulated by the relatively shallow (deep) MLD (Figs. 6c,e). The ocean heat budget in the models also reaffirms our hypothesis on the role of the MLD in modulating the WES feedback (Fig. 7). However, the SSTA growth rate in the models is approximately half of that in reanalysis (cf. Figs. 4c and 7c), possibly because of the overall weaker heat flux anomalies (Fig. 7b) compared to reanalysis (Fig. 4b).

Overall, the inconsistencies in the leading MCA pattern (Fig. S1) within the models along with the 

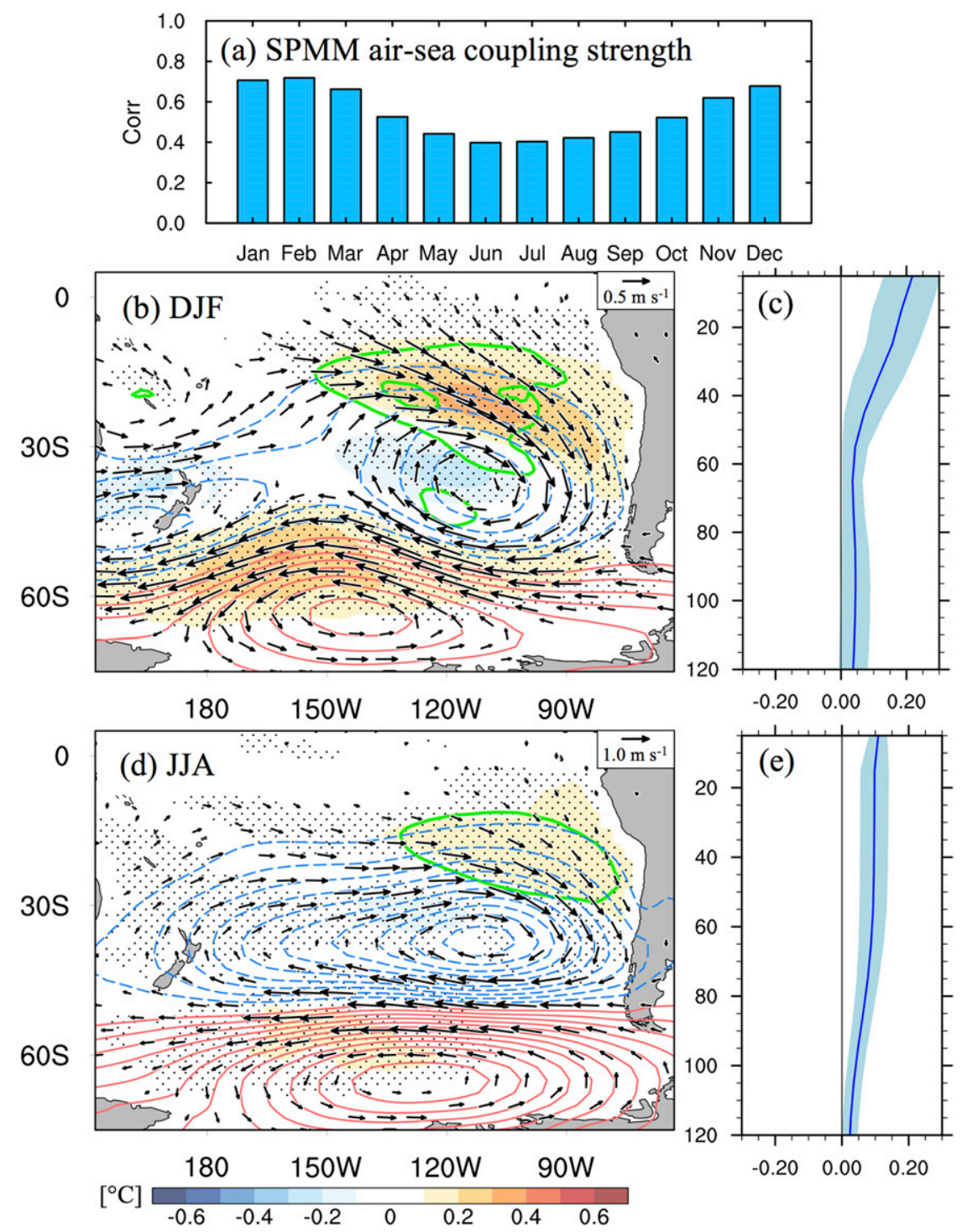

FIG. 6. As in Fig. 3, but for the CMIP5 MME. The SLPA contour interval is $0.2 \mathrm{hPa}$ (blue/red contours) in (b) and (d). The latent heat flux contour interval is $2 \mathrm{~W} \mathrm{~m}^{-2}$ in (b) and $4 \mathrm{~W} \mathrm{~m}^{-2}$ in (d). The reference wind vector is $0.5 \mathrm{~m} \mathrm{~s}^{-1}$ in (b) and $1.0 \mathrm{~m} \mathrm{~s}^{-1}$ in (d). Shading in (c) and (e) indicates the unit standard deviation across the different ensemble members. Stippling in (b) and (d) denotes statistical significance of SSTA (i.e., at least 9 out of 12 model have the same sign of the anomaly).

weaker SSTA growth rate associated with the SPMM dynamics raise the question as to whether these differences are attributable to poor representation of the South Pacific atmospheric intrinsic variability in the models or issues with air-sea coupling resulting from model biases in the background mean state (Zhang et al. 2014b). These differences are beyond the scope of this paper but warrant further investigation. Note, however, that since the CMIP5 models replicate well the temporal statistics and physical processes of the observed SPMM, we will continue to explore the SPMM-ENSO relationship in the CMIP5 models.

\section{Linking the SPMM to ENSO variability and predictability}

Currently, theories on ENSO evolution and dynamics are split on the predictability limit of the phenomenon. The delayed oscillator (Suarez and Schopf 1988) and the recharge oscillator (Jin 1997) theories interpret ENSO as a self-sustained, unstable oscillatory mode 

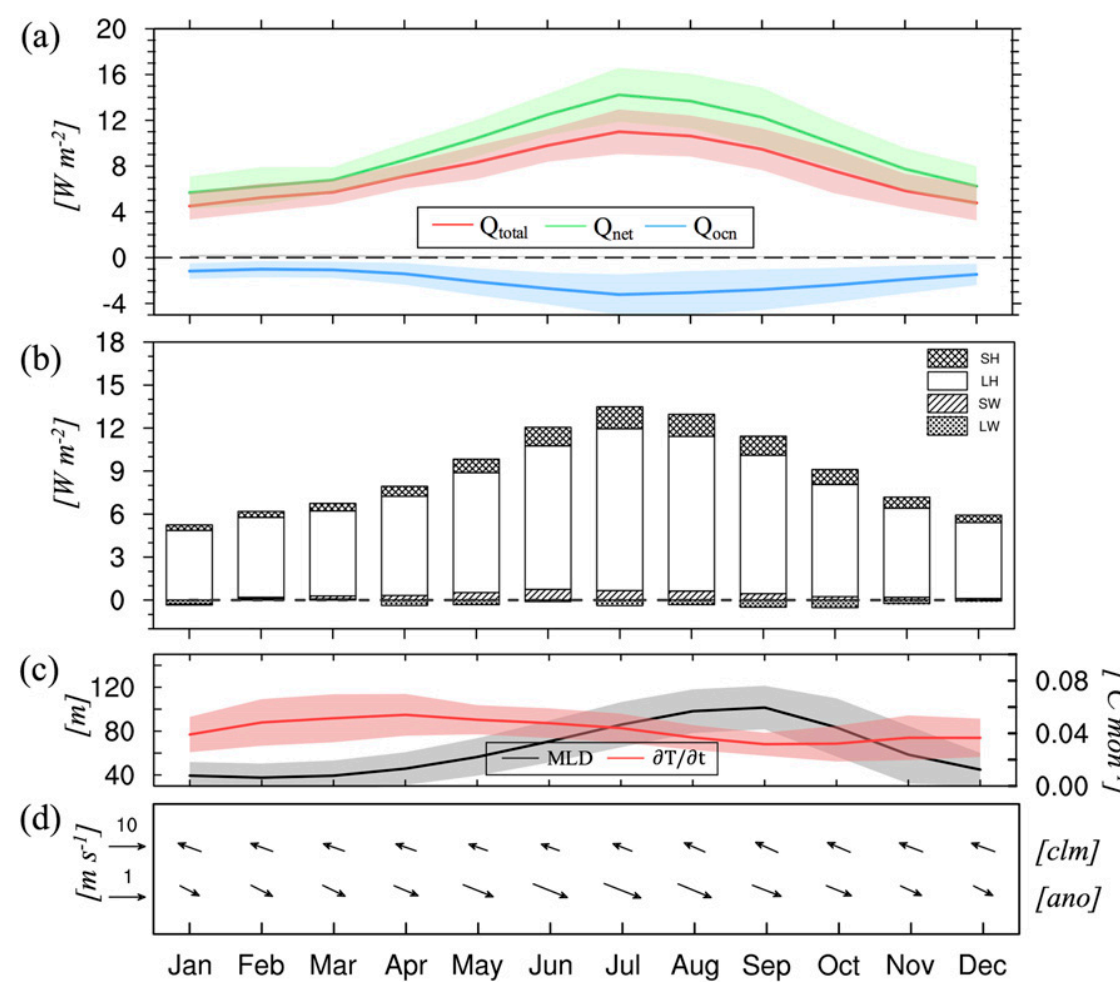

FIG. 7. As in Fig. 4, but for the CMIP5 MME. Shading in (a) and (c) indicates the unit standard deviation across the different ensemble members.

with predictable time scale up to 2 years. Other studies (e.g., Penland and Sardeshmukh 1995) describe ENSO as a stable mode triggered by stochastic forcing, thus suggesting limited predictability. In this section, we examine the roles of the meridional modes and slowly evolving tropical Pacific heat content in ENSO variability and predictability. In particular, we challenge the spring predictability barrier plaguing ENSO predictability studies by showing increased long-lead (6-9 months) forecast skill of tropical Pacific SSTA (i.e., ENSO) using both the NPMM and the SPMM. As we will show, the SPMM aids in extending ENSO predictability back into the boreal spring before the event.

Figure 8 depicts the seasonal evolution of the Pacific atmosphere and ocean anomalies by linearly regressing select variables onto the February-April (FMA)-averaged SPMM index (SPMM FMA $_{\text {A }}$ ) in reanalysis (Figs. 8a-d) and in the MME (Figs. 8e-h). Because the SPMM air-sea coupling strength experiences a clear seasonal cycle (Fig. 3), for this analysis, we highlight this seasonality by defining the SPMM index as the EC- $1_{\text {wind }}$ time series of the MCA of FMA-averaged 10-m wind anomalies and SSTA. Results and conclusions are similar if monthly fields are used instead (not shown). During FMA, the SPMMinduced anomalous low-level winds and SSTA in the southeastern Pacific propagate northwestward into the central-eastern equatorial Pacific via the WES feedback (Figs. 8a,b). The relaxation of the trade winds subsequently suppresses the local upwelling, enhances equatorial eastward-flowing currents, and triggers oceanic Kelvin waves. These three features lead to anomalous zonal advection and a deepened thermocline that facilitate subsequent amplification of equatorial Pacific SSTA (Figs. 8b-d). The CMIP5 MME replicates the observed evolution well but with reduced magnitude

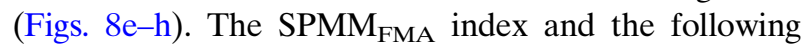
winter's CTI [i.e., $\mathrm{CTI}_{\mathrm{NDJ}(+1)}$ ] are significantly correlated in both reanalysis $(r=0.49, p<0.05$; Fig. 9 c) and the CMIP5 MME ( $r=0.31$; Fig. 9g). The correlation values are comparable in magnitude to the well-identified $\mathrm{NPMM}^{1}$ precursor $(r=0.50 ; p<0.05$ in reanalysis; $r=$ $0.30 ; p<0.05$ in the CMIP5 MME; Figs. 9b,f). As such, the SPMM appears to play an important role in the tropical Pacific SSTA variability, comparable to the role of the NPMM pathway.

\footnotetext{
${ }^{1}$ The NPMM is defined as the MCA- 1 of the monthly SSTA and $10-\mathrm{m}$ wind anomalies over $21^{\circ} \mathrm{S}-32^{\circ} \mathrm{N}, 175^{\circ} \mathrm{E}-95^{\circ} \mathrm{W}$ after subtracting the CTI (Chiang and Vimont 2004). See also https://www.esrl. noaa.gov/psd/data/timeseries/monthly/PMM/.
} 

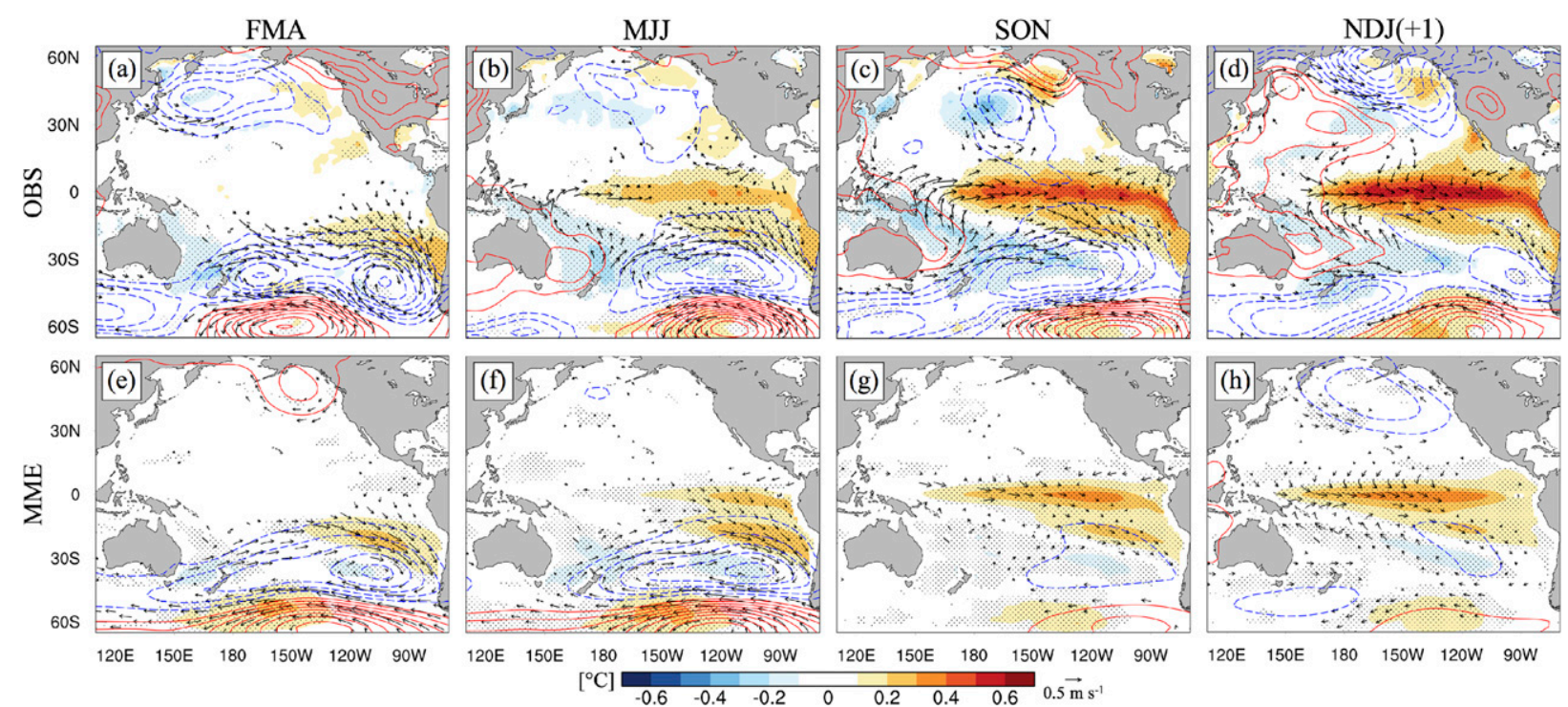

FIG. 8. Lag regression of observed (a) February-April (FMA), (b) May-July (MJJ), (c) August-October (ASO), and (d) NovemberJanuary [NDJ(+1)] SSTA (shading; ${ }^{\circ} \mathrm{C}$ ), SLPA (blue/red contours; $\mathrm{hPa}$ ), and surface wind anomalies (vectors; $\mathrm{m} \mathrm{s}^{-1}$ ) onto the SPMM $\mathrm{FMA}$ index. (e)-(h) As in (a)-(d), but for the CMIP5 MME. The line contour interval is $0.2 \mathrm{hPa}$. The reference vector is $0.5 \mathrm{~m} \mathrm{~s}{ }^{-1}$. Stippling indicates where the SSTA regression coefficients are considered significant (i.e., $p<0.05$ for reanalysis; 9 out of 12 models have the same sign of the regression coefficient for the CMIP5 MME).

\section{a. Contributions of the NPMM and the SPMM to ENSO diversity}

Since the NPMM and the SPMM are contemporaneously independent of each other $(r=0.17$ in observations, $r=0.02$ in MME; Figs. 9a,e), we next investigate how different combinations of the two phases of the meridional modes (i.e., positive or negative) contribute to ENSO diversity (e.g., occurrence, intensity, and flavors). Here the positive (negative) phase of each meridional mode represents the atmospheric and oceanic anomalies that favor El Niño (La Niña) events.

As shown in Figs. 9b and 9c, although the NPMM and SPMM in reanalysis are significantly correlated with $\mathrm{CTI}_{\mathrm{NDJ}(+1)}$, these relationships are conditional; that is, the relationship depends on the phase of the other meridional mode. For example, when the NPMM and SPMM are both positive or both negative, lagged correlations of each meridional mode with the $\mathrm{CTI}_{\mathrm{NDJ}(+1)}$ increase $(r \approx$ 0.6 for reanalysis; $r \approx 0.5$ for the MME; Figs. $9 \mathrm{~b}, \mathrm{c}, \mathrm{f}, \mathrm{g})$. However, when the NPMM and SPMM are of opposite sign, the lagged correlation between each mode and $\mathrm{CTI}_{\mathrm{NDJ}(+1)}$ drops considerably. We note, however, the change in the correlation between same-signed and oppositesigned cases is greater for the SPMM (corr_diff = $0.68 ; p<0.05$ ) than the NPMM (corr_diff $=0.45, p<$ 0.05; see histogram insets in Figs. 9b,c). This is different from the CMIP5 MME where the correlation change is comparable for both the NPMM and SPMM (corr_diff $\approx$
$0.3, p<0.05$; Figs. 9f,g). Nevertheless, these significant changes in the correlation of either mode with tropical Pacific SSTA suggest that this conditional relationship merits consideration for understanding and predicting ENSO variability.

To link these correlation differences to ENSO events, we plot the histogram of the $\mathrm{CTI}_{\mathrm{NDJ}(+1)}$ as a function of the conditional phases of the meridional modes: the NPMM and SPMM of the same sign (two cases; both positive and both negative) and the NPMM and SPMM of the opposite sign (two cases; Figs. 9d,h). The subdivisions are done solely based on the sign of the meridional modes and not on their amplitude, as we wish to preserve as many samples as possible for the histograms. In reanalysis (Fig. 9d), more than $80 \%$ of extreme ENSO episodes $\left[\left|\mathrm{CTI}_{\mathrm{NDJ}(+1)}\right|>1^{\circ} \mathrm{C}\right]$ occur when the NPMM and SPMM are of same sign, namely, both positive (negative) for extreme El Niño (La Niña) events (Fig. 9d). Similarly, more than $50 \%$ of the weak events $\left[\left|\mathrm{CTI}_{\mathrm{NDJ}(+1)}\right|<1^{\circ} \mathrm{C}\right]$ occur when the two meridional modes are of opposite sign. These relationships are generally reproduced in the CMIP5 models (Fig. 9h), although the proportion of the extreme events explained by the same-signed NPMM and SPMM is lower than in reanalysis. One reason, of course, is the thousand-fold difference in sample size between the models and reanalysis, which widens the distribution. Thus, the reanalysis results may be influenced by the limited number of moderate and extreme warm and 

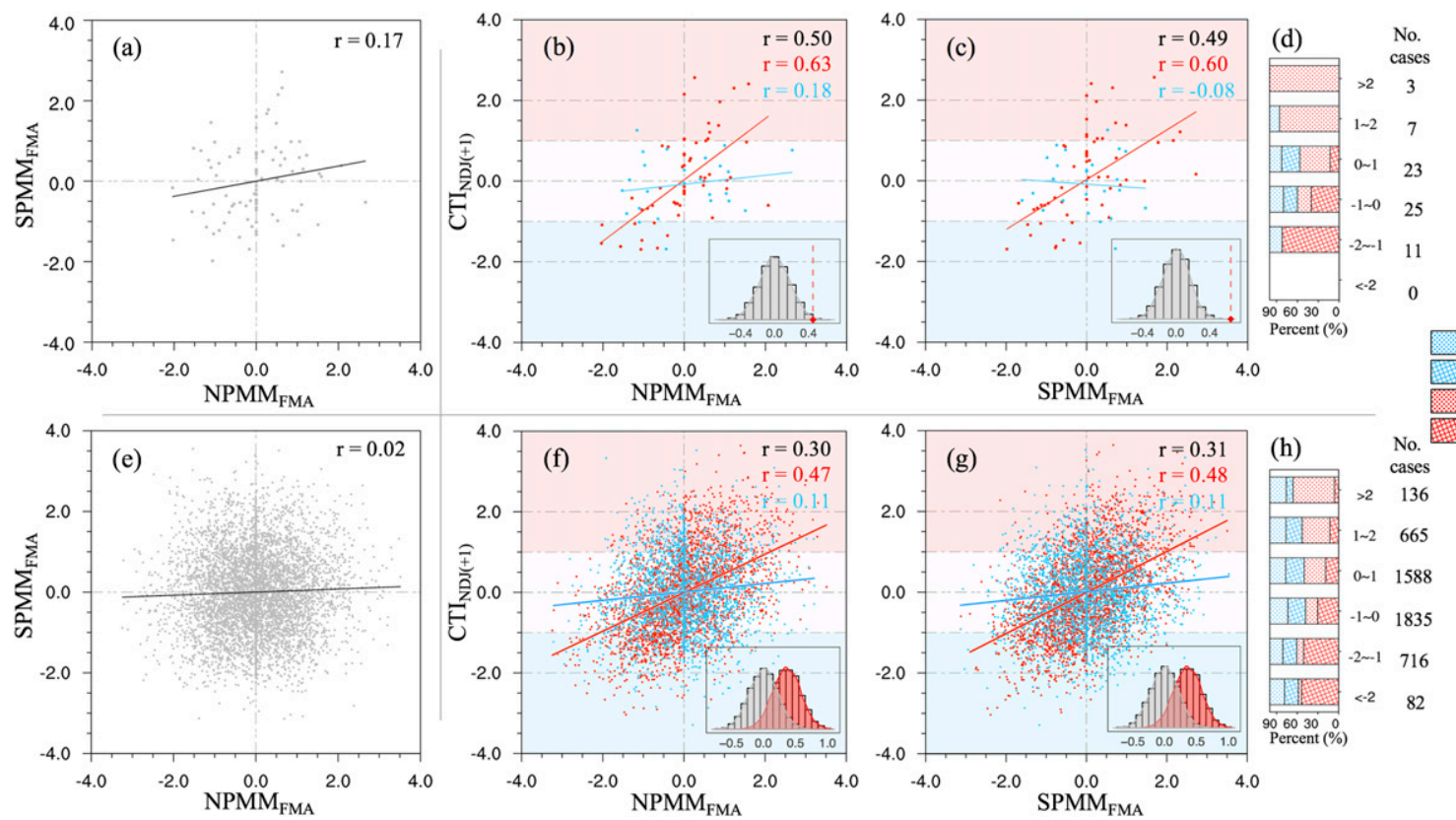

OBS

NPMM-\&SPMM+ NPMM+\&SPMM NPMM+\&SPMM+ NPMM-\&SPMM

FIG. 9. (a) Scatterplot of the NPMM $\mathrm{FMA}_{\mathrm{F}}$ vs $\mathrm{SPMM}_{\mathrm{FMA}}$ indices from reanalysis. The least squares best fit line and correlation are included. (b) Scatterplot of NPMM $\mathrm{FMA}_{\mathrm{N}} \mathrm{vs}_{\mathrm{CTI}} \mathrm{NDJ(+1)}$ values from reanalysis. Red (blue) dots represent years when the NPMM $\mathrm{FMA}_{\mathrm{A}}$ and SPMM $_{\mathrm{FMA}}$ are of same (opposite) sign. Threshold values for each case shown with the red and blue background shading. Corresponding colored lines denote the least squares fit line of the respectively colored dots. Correlation for all points (black) and the correlations for each case (red and blue) included. The inset shows the probability distribution function of the difference in correlation coefficients between same-signed and opposite-signed conditional correlations (i.e., red and blue; see text for details). The red dot in the inset denotes the observed correlation difference (i.e., red minus blue). (c) As in (b), but for the SPMM $\mathrm{FMA}_{\mathrm{Vs}} \mathrm{CTI}_{\mathrm{NDJ}(+1)}$ values. (d) Histogram of frequency (\%) of $\mathrm{CTI}_{\mathrm{NDJ}(+1)}$ values for same-signed and opposite-signed NPMM/SPMM pairings (see legend on far right). Total samples in each bin included. (e)-(h) As in (a)-(d), but for the CMIP5 models. For insets in (f) and (g), the gray (red) PDFs represents corr_diff $\left(\mathrm{SPMM}_{\mathrm{FMA}}\right)$ [corr_diff(NPMM $\left.\mathrm{FMA}_{\mathrm{FA}}\right)$.

cold ENSO events. Another reason for this difference, however, is more dynamical and relates to model biases (i.e., the models systematically underestimate the impact of the meridional modes on ENSO variability).

To evaluate how tropical Pacific SSTA evolve when the NPMM and SPMM are of opposite sign, we next examine conditional regression fields, that is, the lag regression of atmospheric and oceanic fields onto the $\mathrm{NPMM}_{\mathrm{FMA}} / \mathrm{SPMM}_{\mathrm{FMA}}$ index but only for times when the NPMM and SPMM are of opposite sign (i.e., blue dots in Fig. 9). For brevity, we will refer to each case by the index upon which the fields are regressed (i.e., $\mathrm{NPMM}_{\mathrm{FMA}} / \mathrm{SPMM}_{\mathrm{FMA}}$ conditional regressions). Figure 10 shows the seasonal evolution of the Pacific atmosphere and ocean obtained by conditional regression in reanalysis (Figs. 10a-h) and the CMIP5 MME (Figs. 10i-p). During FMA, the two meridional modes produce their characteristic SSTA footprints and modulate the strength of the trade winds in their respective hemisphere (Figs. 10a,e). Since the thermocline feedback is hampered by the opposing wind stress anomalies in the equatorial Pacific induced by the opposite-signed meridional modes, the generation and subsequent eastward propagation of oceanic Kelvin waves are also suppressed, limiting SSTA growth and damping the Bjerknes feedback critical for ENSO development (Figs. 10b,f). Thus, the tropical Pacific SSTA remain almost unchanged spatially throughout the period (Figs. 10d,h). These results reaffirm our findings in Fig. 9 that the development of ENSO events relies on the phase (and likely amplitude) of both meridional modes. Moreover, for $\mathrm{NPMM}_{\mathrm{FMA}}$ conditional regressions, the NPMM-induced tropical SSTA are confined to the central tropical Pacific, resembling CP ENSO events (Fig. 10d). Conversely, a canonical EP-type ENSO event develops when the two meridional modes are in same phase (Fig. S2). As such, not only does the SPMM play a role in tropical Pacific dynamics, but it may also contribute to the flavor of the resulting ENSO events.

The CMIP5 MME yields similar evolutions during FMA and May-July (MJJ) as the reanalysis (Figs. 10i,j,m,n), but differences emerge thereafter and especially during the peak season of ENSO. For NPMM FMA conditional regressions, the SSTA span the entire equatorial Pacific strip (Fig. 101), unlike the more CP ENSO-like condition seen in reanalysis (Fig. 10d). Conversely, for $\mathrm{SPMM}_{\mathrm{FMA}}$ conditional regressions, the equatorial Pacific strip is nearly 

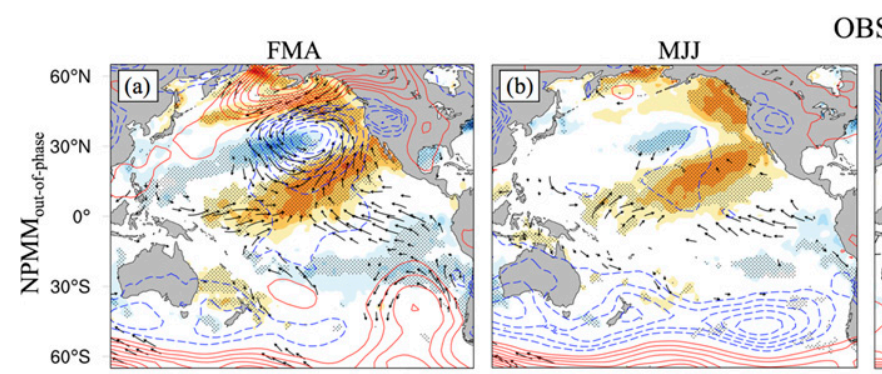

OBS ASO
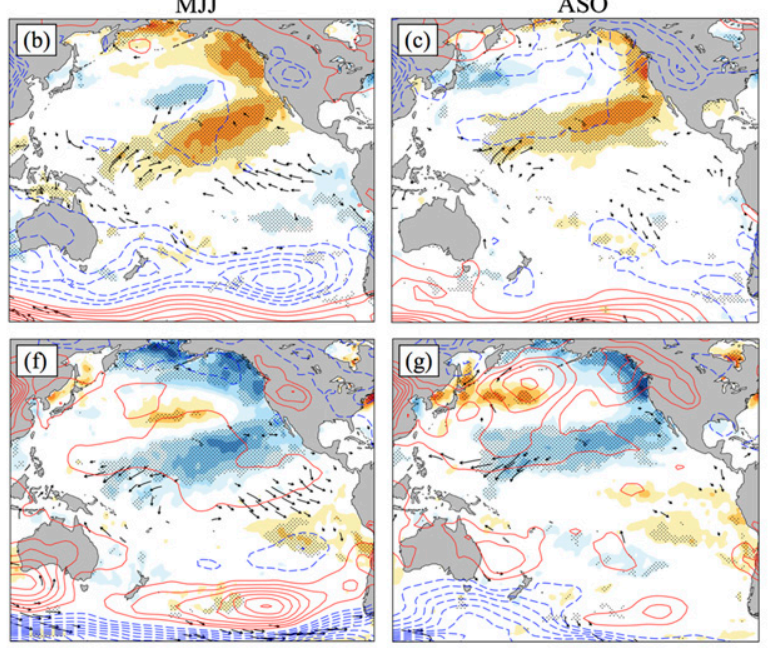

MME
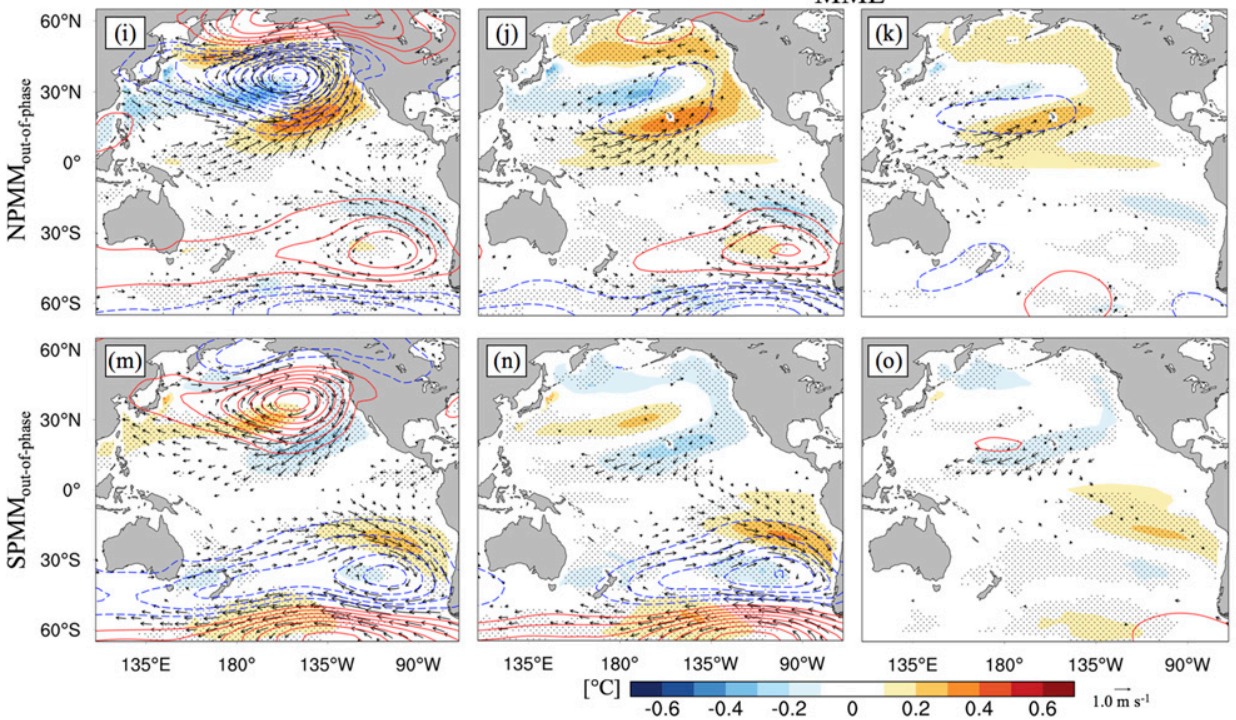

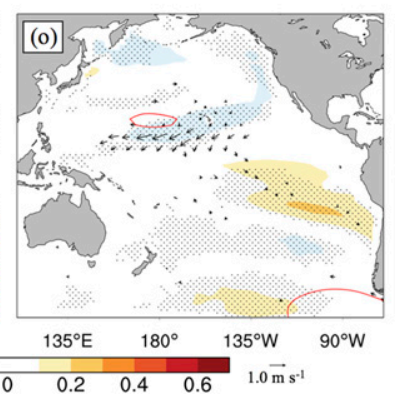

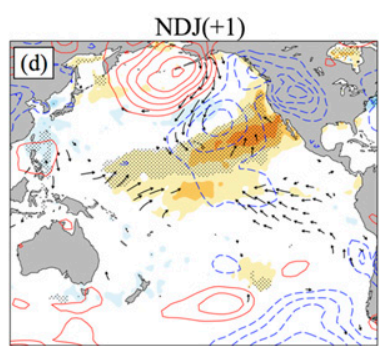
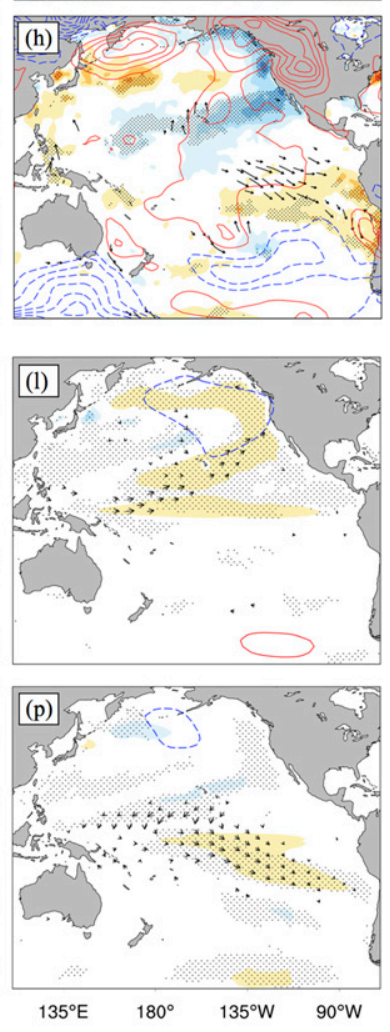

FIG. 10. Lag regression of observed (a) FMA, (b) MJJ, (c) ASO, and (d) NDJ(+1) SSTA (shading; $\left.{ }^{\circ} \mathrm{C}\right)$, SLPA (blue/red contours; hPa) and surface wind anomalies (vectors; $\mathrm{m} \mathrm{s}^{-1}$ ) onto the standardized NPMM $_{\mathrm{FMA}}$ index under the condition that the NPMM $\mathrm{FMA}$ and

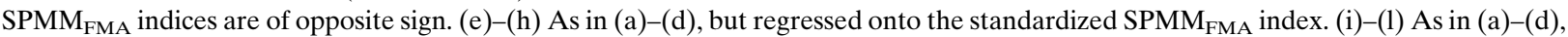
but for the CMIP5 MME. (m)-(p) As in (e)-(h), but for the CMIP5 MME. The line contour interval is $0.2 \mathrm{hPa}$. The reference vector is $1.0 \mathrm{~m} \mathrm{~s}^{-1}$. Stippling indicates where the SSTA regression coefficients are considered significant $(p<0.05$ for reanalysis; 9 out of 12 models have the same sign of the regression coefficient for the CMIP5 MME).

devoid of any significant SSTA (Fig. 10p). Known biases and issues that climate models possess with simulating different ENSO flavors likely factor into this result (e.g., Kim and $\mathrm{Yu}$ 2012), indicating that caution may be needed when studying the predictability or future projections of ENSO activity using these models.

\section{b. Sensitivity of the impacts of meridional modes to equatorial Pacific heat content}

Thus far, we have examined how the NPMM and SPMM contribute to the development of ENSO events. However, equatorial Pacific heat content, which leads the ENSO by a quarter cycle, is often considered a necessary precondition for the development of an ENSO event (e.g., Meinen and McPhaden 2000; Anderson 2007; Deser et al. 2012; Larson and Kirtman 2014). Hence, we explore the sensitivity of the influences of the NPMM and the SPMM to the equatorial Pacific heat content, represented here by warm water volume.

Figure 11 is similar to Fig. 9 except this time we consider the conditional relationship between each meridional mode and WWV during FMA ( $\left.W W V_{F M A}\right)$. Here, positive (negative) WWV values indicate that tropical Pacific heat content is anomalously positive (negative). 

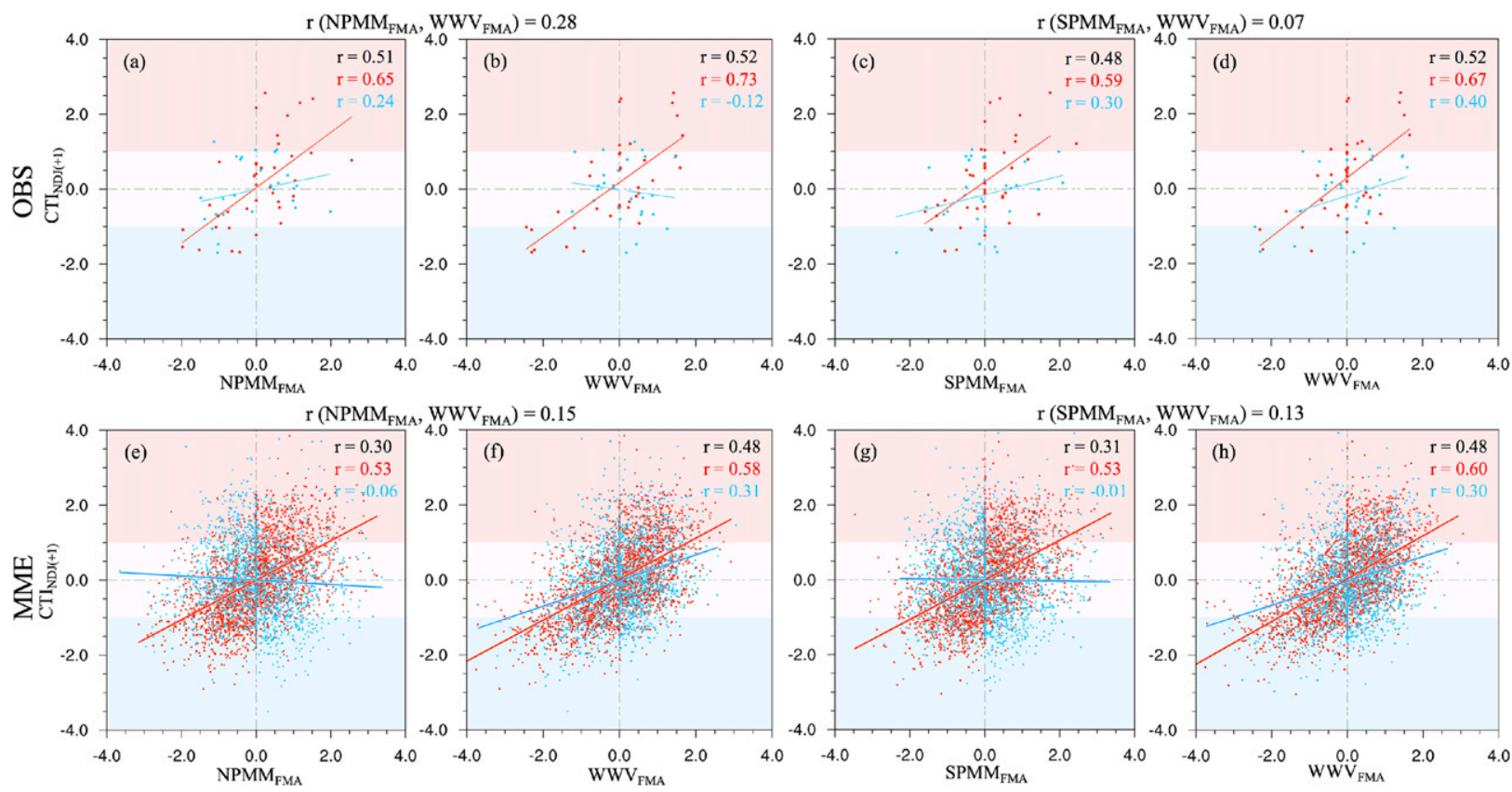

FIG. 11. (a) Scatterplot of the observed NPMM $\mathrm{FMA}_{\mathrm{FA}}$ and $\mathrm{CTI}_{\mathrm{NDJ}(+1)}$ values when the $\mathrm{NPMM}_{\mathrm{FMA}}$ is the same (red dots) and opposite (blue dots) sign with respect to the $\mathrm{WWV}_{\mathrm{FMA}}$ anomaly. Threshold values for each case shown with the red and blue background shading. Corresponding colored lines denote the least squares fit line of the respectively colored dots. Correlation for all points (black) and the conditional correlations for each case (red and blue) included. (b) As in (a), but for the $\mathrm{WWV}_{\mathrm{FMA}}$ and CTI $\mathrm{NDJ}_{(+1)}$ values. (c) As in (a), but for the observed SPMM $\mathrm{FMA}_{\text {and }}$ CTI $\mathrm{NDJ}_{(+1)}$ values when the SPMM $\mathrm{FMA}_{\mathrm{A}}$ is of the same (red dots) and opposite (blue dots) sign with the $\mathrm{WWV}_{\mathrm{FMA}}$ anomaly. (d) As in (c), but for the WWV FMA and CTI $\mathrm{WDJ}_{\mathrm{F}(+1)}$ values. (e)-(h) As in (a)-(d), but for the CMIP5 models.

When the NPMM $\mathrm{FMA}_{\mathrm{F}}$ and $\mathrm{WWV}$ FMA are of opposite sign, the correlation between $\mathrm{WWV}_{\mathrm{FMA}}$ and $\mathrm{CTI}_{\mathrm{NDJ}(+1)}$ is small and negative $(r=-0.12$; Fig. 11a). The difference in the WWV-ENSO correlation for cases with and without a same-signed NPMM is 0.85 (Fig. 11b). Hence, the $\mathrm{WWV}_{\mathrm{FMA}}$ alone appears insufficient as a precursor to ENSO since there is a strong dependence on NPMM-related wind forcing and the TWC mechanism (Anderson and Perez 2015). The SPMM $_{\mathrm{FMA}}$, by contrast, has a negligible correlation with $\mathrm{WWV}_{\mathrm{FMA}}(r=0.07)$ as the SPMM-related wind curl is directed eastward and thus favors Sverdrup transport toward the South American coast (not shown). As such, the SPMM is not associated with the TWC mechanism. Nonetheless, same-signed $\mathrm{WWV}_{\mathrm{FMA}}$ anomalies appear important for the SPMM to initiate ENSO events (corr_diff $=0.29$; Figs. 11c). The importance of the SPMM forcing to the WWVENSO relationship is comparable (corr_diff $=0.27$; Fig. 11d).

The CMIP5 models do not simulate well the TWC mechanism as the correlations between either meridional mode and WWV are both low ( $r=0.15$ for NPMM; $r=$ 0.13 for SPMM; Figs. 11e-h). Interestingly, the relationship between the meridional modes and ENSO (corr_diff $0.5)$ is more sensitive to the state of $\mathrm{WWV}_{\mathrm{FMA}}$ than the actual sensitivity between WWV $\mathrm{FMA}_{\text {A }}$ and ENSO (corr diff $\approx 0.3$; Figs. 11e-h). The WWV therefore dominates ENSO predictability in the models, likely because the CMIP5 models generally simulate ENSO variability with a too-short, highly regular period compared to nature (e.g., Bellenger et al. 2014). As such, ENSO behaves more like a self-sustained, regular oscillatory mode in these models.

\section{c. A simple statistical model for predicting Pacific SSTA during boreal winter}

Thus far, we have presented evidence of the relationship between both the NPMM, SPMM, and ENSO along with the importance of the meridional modes versus ocean subsurface memory (i.e., WWV) in ENSO variability. We now put these findings to the test in a simple predictive exercise to quantify the relative roles of the NPMM, SPMM, and WWV in long-lead ENSO prediction. To do so, we construct a simple multivariate statistical model of the form

$$
\begin{aligned}
\operatorname{SSTA}_{\mathrm{NDJ}(+1)}(x, t)= & a(x) \times \mathrm{NPMM}_{\mathrm{FMA}(t)} \\
& +b(x) \times \operatorname{SPMM}_{\mathrm{FMA}}(t) \\
& +c(x) \times \mathrm{WWV}_{\mathrm{FMA}}(t)+\varepsilon,
\end{aligned}
$$



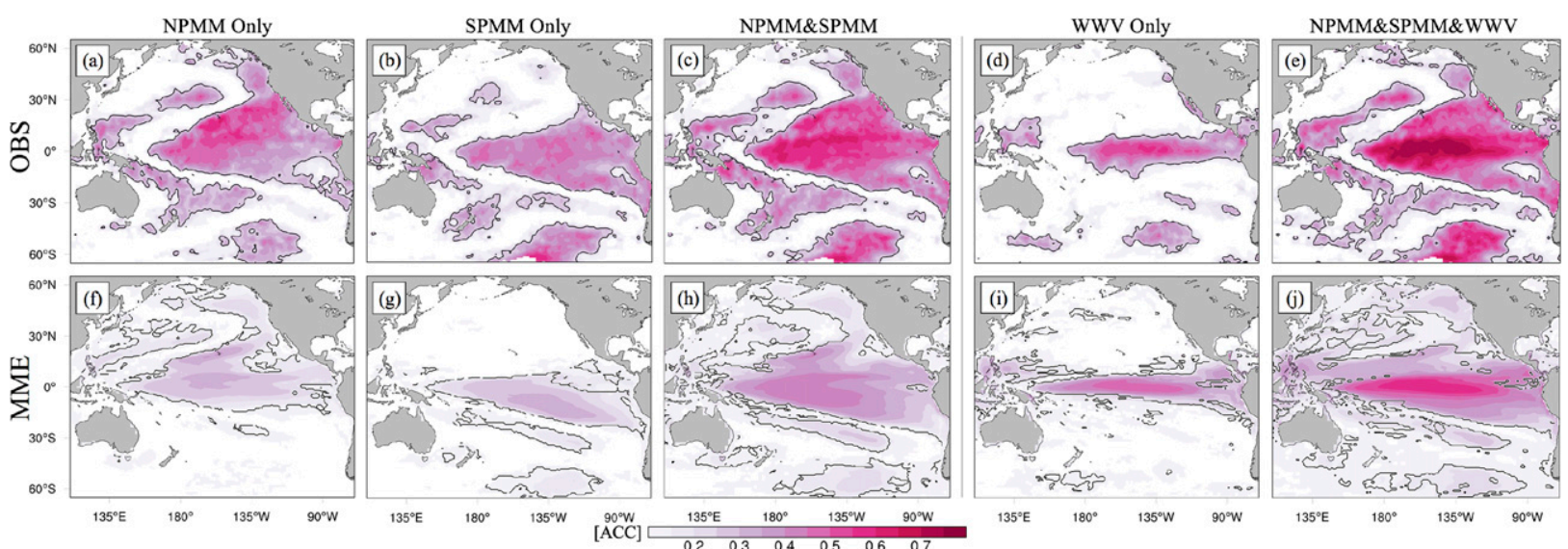

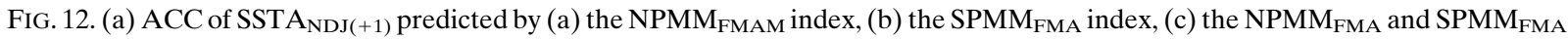
indices, (d) the $\mathrm{WWV}_{\mathrm{FMA}}$ index, and (e) the NPMM $\mathrm{NMA}_{\mathrm{FM}}, \mathrm{SPMM}_{\mathrm{FMA}}$, and WWV $\mathrm{WMA}_{\mathrm{FM}}$ indices using a simple linear regression model (see text). (f)-(j) As in (a)-(e), but for the CMIP5 MME. Black contours outline where ACC values are significant at the $95 \%$ confidence level per a Monte Carlo test.

where $x$ is the spatial coordinate, $t$ is time, and $a, b$, and $c$ are the regression coefficients determined by least squares fitting. This model is run using one, two, and all three predictors to examine the sensitivity of our hindcasts to each predictor. The target variable is SSTA throughout the Pacific basin rather than a single index as others have done previously (e.g., Ding et al. 2017), thus allowing us to score the actual skill of the model in predicting the amplitude and structure of ENSO events. Forecast skill (measured here as relative to climatology) of the statistical model hindcasts is quantified through the anomaly correlation coefficient (ACC; Miyakoda et al. 1972), that is,

$$
\mathrm{ACC}=\frac{\sum_{t=1}^{T} f_{t} v_{t}}{\sqrt{\sum_{t=1}^{T} f_{t}^{2}} \sqrt{\sum_{t=1}^{T} v_{t}^{2}}}
$$

where $f_{t}$ is the forecast value, and $v_{t}$ is the observed (or simulated) value at time $t$. The leave-one-out crossvalidation scheme is applied to reduce overfitting (Elsner and Schmertmann 1994).

Figure 12 summarizes the performance of the statistical model. In reanalysis, when using only the $\mathrm{NPMM}_{\mathrm{FMA}}$ index as a predictor, high ACC values prevail in the subtropical North Pacific and the central tropical Pacific with lower ACC values in the far eastern tropical Pacific (Fig. 12a). Conversely, when using the $S_{P M M} M_{F M A}$ index only as a predictor, high ACC values are located over the eastern equatorial and subtropical Pacific (Fig. 12b). These areas of maximum ACC agree with our earlier analysis on how tropical Pacific SSTA correlate with each meridional mode. Using both the $\mathrm{NPMM}_{\mathrm{FMA}}$ and $\mathrm{SPMM}_{\mathrm{FMA}}$ indices in the statistical model captures a significant fraction of the tropical and subtropical Pacific $\operatorname{SSTA}_{\mathrm{NDJ}(+1)}$ variance versus using only one (Fig. 12c). As such, combining the two meridional modes significantly enhances forecast skill in the Pacific basin (Fig. 12c). By contrast, using only $\mathrm{WWV}_{\mathrm{FMA}}$ as a predictor restricts forecast skill to a very narrow belt over the equatorial Pacific (Fig. 12d). Although $\mathrm{WWV}_{\mathrm{FMA}}$ alone would fare poorly as a predictor for extratropical Pacific SSTA, it elevates ACC values in the central-to-eastern tropical Pacific when combined with the two meridional modes (Fig. 12e). We also note that the prediction skill of this empirical statistical model is comparable to linear inverse models and is higher than that of a univariate first-order autoregressive scheme (e.g., Alexander et al. 2008). Overall, the results from reanalysis indicate that the NPMM and SPMM together are the most significant predictors of the three for ENSO variability.

Applying the same statistical model to the CMIP5 models, the predictive power of the model is overall lower compared to reanalysis (Figs. $12 \mathrm{f}-\mathrm{j}$ ) partly because of a larger sample size. However, other important differences are also evident. For example, using only the SPMM $\mathrm{FMA}_{\mathrm{F}}$ index as a predictor, the highest scores $(\mathrm{ACC} \approx 0.3)$ reside from the central equatorial Pacific southward to about $5^{\circ}-15^{\circ} \mathrm{S}$ (Fig. $12 \mathrm{~g}$ ). Although ACC values increase when using both the $\mathrm{SPMM}_{\mathrm{FMA}}$ and NPMM $_{F M A}$ indices as predictors in the CMIP5 MME, these values are about half of that of from observations (Fig. 12h). Instead, the highest ACC scores for the CMIP5 MME occur when using WWV $_{\mathrm{FMA}}$ index as a 
predictor, whose sole contribution explains more of the variance in equatorial Pacific SSTA than the two meridional modes used together (Fig. 12i). This result suggests that the CMIP5 models are overly sensitive to conditions in the tropical Pacific themselves for ENSO predictability rather than capturing the extratropical precursors (i.e., the NPMM and the SPMM). Thus, there may be actual important coupled ocean-atmosphere dynamics originating from the extratropics missing from the models, potentially limiting their use for studying ENSO predictability and even ENSO variability under future climate change.

\section{Summary and discussion}

This study explored the characteristics of the South Pacific meridional mode (SPMM) and its influence on the El Niño-Southern Oscillation (ENSO) phenomenon. The SPMM emerges as a robust thermodynamically coupled mode associated with the local atmospheric internal variability, which organizes into the large-scale meridional sea level pressure anomaly (SLPA) dipole (Figs. 1 and 2). The SPMM-associated WES feedback is most energetic during the cold season due to a shallower oceanic mixed layer (Figs. 3 and 4), so that the SPMM operates as an effective conduit for South Pacific austral summer and fall atmospheric and oceanic anomalies to propagate into the tropics and thereafter contribute to the onset of ENSO events. The constructive and destructive interference between the austral summer North Pacific meridional mode (NPMM)- and SPMM-induced tropical Pacific anomalies regulate the occurrence, evolution, intensity, and potentially the flavor of ENSO events, thus contributing substantially to ENSO diversity. Both meridional modes are most efficient at triggering ENSO events when the equatorial Pacific is preconditioned with anomalous ocean heat content buildup. Incorporating the two meridional modes into a simple statistical predictive model increases tropical Pacific SSTA prediction skill with a 6-9-month lead time (Fig. 12), suggesting a path forward to reducing the existing spring predictability barrier currently plaguing ENSO seasonal forecasts.

This study goes further by exploring the CMIP5 models, in which the close correspondence of the major features of the SPMM and the SPMM-induced tropical Pacific anomalies with those in reanalysis bolsters our conclusions. However, the CMIP5 MME underestimate (overestimate) the impacts of the meridional modes (WWV) on ENSO variability (Figs. 11 and 12). While the present study primarily concentrates on the MME mean, we briefly address the intermodel spread in the SPMM-ENSO relationship here. The models analyzed in this study are subdivided into two groups based on the correlation between the $\mathrm{SPMM}_{\mathrm{FMA}}$ and $\mathrm{CTI}_{\mathrm{NDJ}(+1)}$ indices within each model compared to the MME correlation. The two groups are named model $_{\text {high_corr }}$ (i.e., models in which the correlation is higher than the MME mean) and model $l_{\text {low_corr }}$ (i.e., models in which the correlation is lower than the MME mean). Figures 13a-h are similar to Fig. 8 (i.e., lagged regressions onto the $\mathrm{SPMM}_{\mathrm{FMA}}$ index) but for the mean regression for each group. The most evident differences between the two groups of models emerge during and after May-July, when the SSTA and the deepening of thermocline in the eastern tropical $\mathrm{Pa}$ cific are present in the model high_corr $_{\text {(Fig. 13b) group }}$

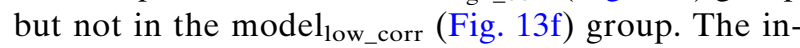
termodel spread in the SPMM-ENSO relationship is likely caused by the cold tongue bias, as ENSOrelated SSTA growth rate is higher when the eastern equatorial SST mean state is warmer (Fig. 13i) and the ascending branch of the Walker circulation shifts eastward (Fig. 13j; see also Lübbecke and McPhaden 2014).

Our study also documented two major differences between the North and South Pacific atmospheric variability associated with each respective meridional mode. First, the amplitude of the mean seasonal cycle in the Southern Hemisphere atmospheric variability is lower than that of the Northern Hemisphere (Figs. 3 and 6; e.g., Kiladis and Mo 1999; Cai and Watterson 2002), which allows the air-sea coupling associated with the SPMM to be most energetic during the austral summer (Figs. 1c and 8). As recent studies have highlighted the impacts of the austral winter South Pacific variability on 2-yr La Niña events (DiNezio et al. 2017) and El Niño flavors (Meehl et al. 2017; You and Furtado 2017), advancing long-lead ENSO prediction skill may stem from observing South Pacific climate variability. Second, akin to the NPO, the atmospheric mode exciting the SPMM features a large-scale SLP dipole (Okumura 2013; Zhang et al. 2014a), closely resembling the socalled South Pacific Oscillation (SPO; You and Furtado 2017). Since tropical Pacific SSTA contribute to the variability in this dipole structure (Figs. 2 and 5; e.g., Cai and Watterson 2002), the SPMM-induced tropical Pacific anomalies, in turn, reinforce the atmospheric driver, potentially forming a fast positive feedback and explaining why the SLPA pattern associated with the SPMM decays slowly compared to the NPO (Figs. 8 and 10). Note that this analysis does not exclude the potential for other related atmospheric modes to excite the SPMM and/or SPO variability. Future work should address this concept.

The current work complements and builds upon an emerging and growing body of literature on the role of 

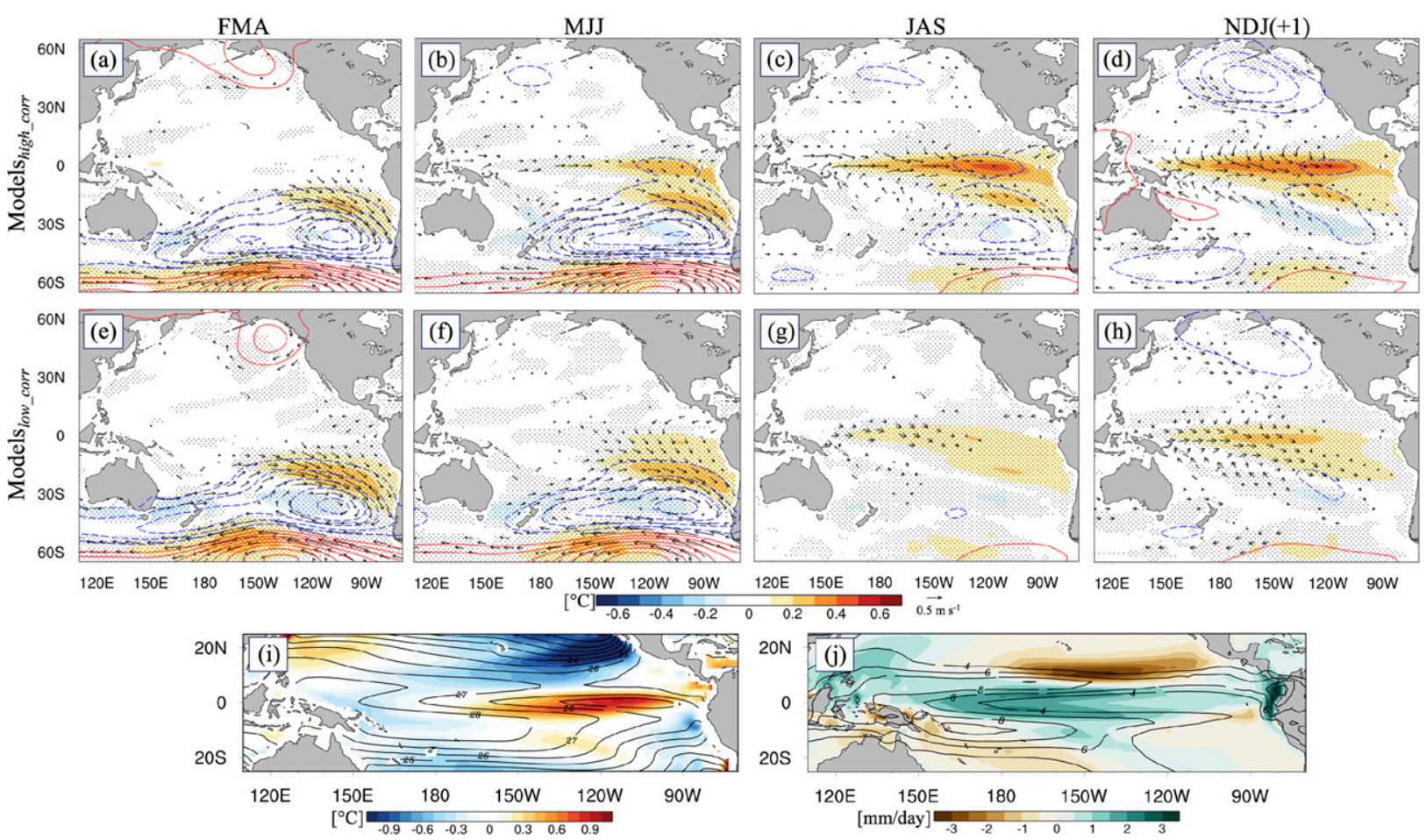

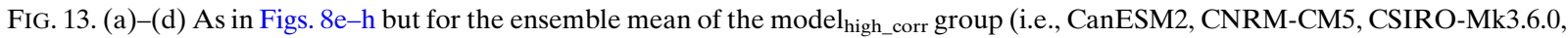

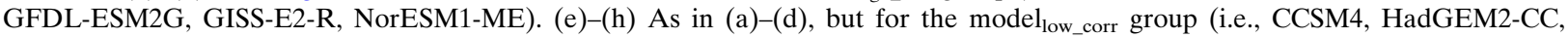
INMCM4, MIROC5, IPSL-CM5A-MR, MPI-ESM-P). Stippling indicates where the SSTA regression coefficients are considered significant (4 out of 6 models have the same sign of the regression coefficient). (i) Mean February-July SST climatology (black contours; ${ }^{\circ} \mathrm{C}$ ) for the model $_{\text {high_corr }}$ models and the difference (shading; ${ }^{\circ} \mathrm{C}$ ) of the February-July SST climatology between the model ${ }_{\text {high_corr }}$ and model $_{\text {low_corr }}$ models. (j) As in (i), but for precipitation $\left(\mathrm{mm} \mathrm{day}^{-1}\right)$.

the meridional modes in Pacific climate variability (e.g., Vimont et al. 2001, 2003a,b; Chang et al. 2007; Okumura 2013; Zhang et al. 2014a; Di Lorenzo et al. 2015; Ding et al. 2017; Min et al. 2017; and references therein). The SPMM (NPMM) initiates anomalies in the eastern Pacific cold tongue (western Pacific warm pool) region. When ocean dynamics are actively involved, the impacts of the two meridional modes on the tropical Pacific are comparable. Although either meridional mode can excite ENSO events, our results emphasize that the interplay between the NPMM and the SPMM is an important element to consider for ENSO diversity (Figs. 9 and 10). When the NPMM and SPMM are of opposite sign, the thermocline feedback is suppressed, whereas the zonal advection feedback, which intensifies in the vicinity of the warm pool, possibly results in the stronger expression of the NPMM in the tropical Pacific (Figs. 10d,h,l,p). This result agrees with that of Ding et al. (2017), although they argue that the modulation of western tropical Pacific wind anomalies (driven in part by a SLPA pattern with a loading center off Australia) is the dominant factor in regulating ENSO development. Min et al. (2017) identify the SPMM in reanalysis and its importance for ENSO variability. However, their EC- $1_{\text {wind }}$ index is significantly correlated with their $\mathrm{EC}-1_{\mathrm{SST}}$ index with a 1-yr lag (their Fig. 3d), and the concurrent atmospheric and oceanic fields related to the SPMM $_{\mathrm{FMA}}$ feature a mature ENSO pattern (their Figs. $6 \mathrm{a}-\mathrm{d}$ ), thus limiting the implication of their SPMM in ENSO prediction. Our definition of the SPMM instead captures lagged relationships between South Pacific and tropical Pacific climate variability, opening the door for longer-lead ENSO predictions. Indeed, the lack of sensitivity of the models to SPMMrelated variability in the ENSO system may result in poor ENSO predictions in statistical and dynamical models (e.g., Landsea and Knaff 2000; Chiodi and Harrison 2017) and also sheds light on past unusual (and misforecasted) ENSO episodes (e.g., Su et al. 2014; $\mathrm{Hu}$ and Fedorov 2016; Imada et al. 2016; You and Furtado 2017).

Finally, there are indications that the meridional modes collectively contribute to Pacific decadal climate variability, expanding the framework proposed by Di Lorenzo et al. (2015) to incorporate the South Pacific. The observed meridional modes show significant 

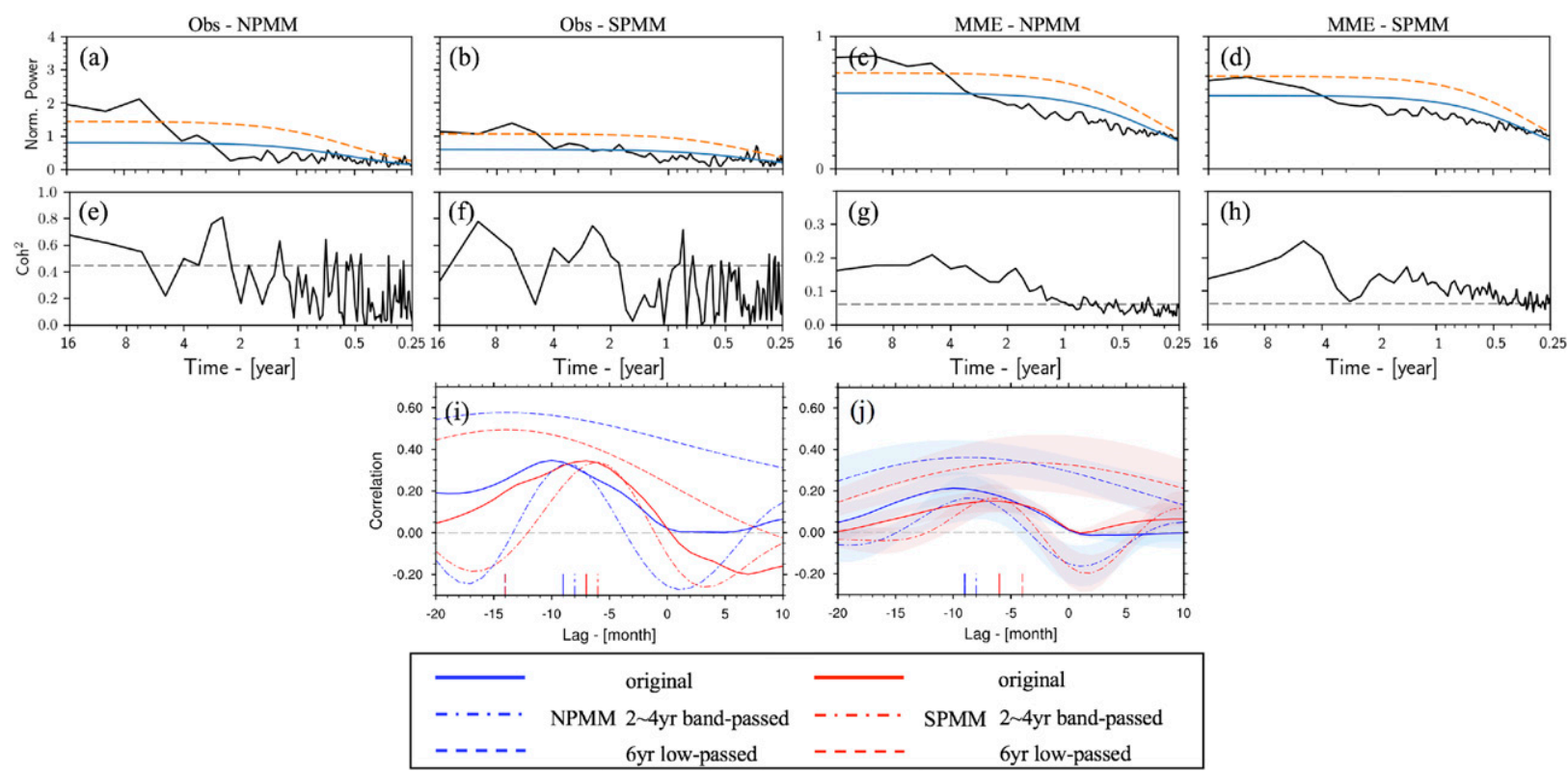

FIG. 14. (a) Power spectrum (plotted as percent variance; black line) of the standardized observed monthly-mean NPMM index. The blue line represents the theoretical red noise power spectrum, and the dashed red line represents the $95 \%$ significance curve. (b) As in (a), but for the observed monthly-mean SPMM index. (c) As in (a), but for the CMIP5 MME. (d) As in (b), but for the CMIP5 MME. (e) Squared coherence from the cross-spectral analysis of the monthly-mean NPMM index and CTI. The dashed gray line denotes the 95\% significance level for the squared coherence. (f) As in (e), but for the cross-spectral analysis of the monthly-mean SPMM index and CTI. (g) As in (e), but for the CMIP5 MME. (h) As in (f), but for the CMIP5 MME. Note the differences of the $y$ axis for the CMIP5 MME vs the reanalysis plots. (i) Lag correlation of the raw (solid), 2-4-yr band-passed (dot dashed), and 6-yr low-passed (dashed) versions of the NPMM (blue) and SPMM (red) indices and the CTI. Negative (positive) lags indicate that the NPMM/SPMM index leads (lags) the CTI. Corresponding vertical lines on the $x$ axis represent the lag with the maximum correlation. (j) As in (i), but for the CMIP5 MME. Red/blue shading in (j) denotes the unit standard deviation across the different ensemble members.

periodicities at and longer than $\sim 5$ years (Figs. 14a,b) and exhibit significant squared coherence with the CTI on interannual time scales ( $2-4$ years) and periods exceeding 6 years (Figs. 14e,f,i). The increasing power at lower frequencies arises partly from midlatitude air-sea coupling (Barsugli and Battisti 1998; Vimont et al. 2003a,b) and possibly tropical Pacific remote forcing (Furtado et al. 2012; Stuecker 2018). The CMIP5 MME agrees with reanalysis but with reduced coherence (Figs. 14g,h). Nevertheless, the short lead time ( $\sim 1$ year) for the meridional modes at low-frequency time scales suggests limited predictability (Figs. 14i,j; e.g., Vimont et al. 2003a; Okumura 2013). Further work on low-frequency meridional modes and Pacific climate variability is therefore warranted.

Acknowledgments. The authors thank two anonymous reviewers for their insightful comments and for helping to improve the manuscript. We would also like to thank the various modeling centers for their contributions to the CMIP5 archive, the National Centers for Environmental Prediction (NCEP) and National Center for Atmospheric Research (NCAR), and the European Center for Medium-Range Weather Forecasts (ECMWF) for the reanalysis products. All reanalysis data and model output are publicly accessible.

\section{REFERENCES}

Alexander, M. A., I. Bladé, M. Newman, J. R. Lanzante, N.-C. Lau, and J. D. Scott, 2002: The atmospheric bridge: The influence of ENSO teleconnections on air-sea interaction over the global oceans. J. Climate, 15, 2205-2231, https://doi.org/10.1175/ 1520-0442(2002)015<2205:TABTIO >2.0.CO;2.

- L. Matrosova, C. Penland, J. D. Scott, and P. Chang, 2008: Forecasting Pacific SSTs: Linear inverse model predictions of the PDO. J. Climate, 21, 385-402, https://doi.org/10.1175/ 2007JCLI1849.1.

— D. J. Vimont, P. Chang, and J. D. Scott, 2010: The impact of extratropical atmospheric variability on ENSO: Testing the seasonal footprinting mechanism using coupled model experiments. J. Climate, 23, 2885-2901, https://doi.org/10.1175/ 2010JCLI3205.1.

Anderson, B. T., 2007: On the joint role of subtropical atmospheric variability and equatorial subsurface heat content anomalies in initiating the onset of ENSO events. J. Climate, 20, 1593-1599, https://doi.org/10.1175/JCLI4075.1.

_ and R. C. Perez, 2015: ENSO and non-ENSO induced charging and discharging of the equatorial Pacific. Climate Dyn., 45, 2309-2327, https://doi.org/10.1007/s00382-015-2472-x. 
Ashok, K., S. K. Behera, S. A. Rao, H. Weng, and T. Yamagata, 2007: El Niño Modoki and its possible teleconnection. J. Geophys. Res., 112, C11007, https://doi.org/10.1029/ 2006 JC003798.

Balmaseda, M. A., K. E. Trenberth, and E. Kallen, 2013: Distinctive climate signals in reanalysis of global ocean heat content. Geophys. Res. Lett., 40, 1754-1759, https://doi.org/10.1002/ grl.50382.

Barnston, A. G., M. K. Tippett, M. L. L'Heureux, S. Li, and D. G. DeWitt, 2012: Skill of real-time seasonal ENSO model predictions during 2002-11: Is our capability increasing? Bull. Amer. Meteor. Soc., 93, 631-651, https://doi.org/10.1175/ BAMS-D-11-00111.1.

Barsugli, J. J., and D. S. Battisti, 1998: The basic effects of atmosphere-ocean thermal coupling on midlatitude variability. J. Atmos. Sci., 55, 477-493, https://doi.org/10.1175/15200469(1998)055<0477:TBEOAO > 2.0.CO; 2 .

— to tropical SST anomalies throughout the Indo-Pacific basin. J. Climate, 15, 3427-3442, https://doi.org/10.1175/1520-0442 (2002) $015<3427$ :GASTTS $>2.0$. CO;2.

Bellenger, H., E. Guilyardi, J. Leloup, M. Lengaigne, and J. Vialard, 2014: ENSO representation in climate models: From CMIP3 to CMIP5. Climate Dyn., 42, 1999-2018, https:// doi.org/10.1007/s00382-013-1783-z.

Bretherton, C. S., C. Smith, and J. M. Wallace, 1992: An intercomparison of methods for finding coupled patterns in climate data. J. Climate, 5, 541-560, https://doi.org/10.1175/ 1520-0442(1992)005<0541:AIOMFF >2.0.CO;2.

_ , M. Widmann, V. P. Dymnikov, J. M. Wallace, and I. Bladé, 1999: The effective number of spatial degrees of freedom of a time-varying field. J. Climate, 12, 1990-2009, https://doi.org/ 10.1175/1520-0442(1999)012<1990:TENOSD>2.0.CO;2.

Cai, W., and I. G. Watterson, 2002: Modes of interannual variability of the Southern Hemisphere circulation simulated by the CSIRO climate model. J. Climate, 15, 1159-1174, https://doi.org/ 10.1175/1520-0442(2002)015<1159:MOIVOT>2.0.CO;2.

Capotondi, A., and Coauthors, 2015: Understanding ENSO diversity. Bull. Amer. Meteor. Soc., 96, 921-938, https://doi.org/ 10.1175/BAMS-D-13-00117.1.

Carton, J. A., and B. S. Giese, 2008: A reanalysis of ocean climate using Simple Ocean Data Assimilation (SODA). Mon. Wea. Rev., 136, 2999-3017, https://doi.org/10.1175/ 2007MWR1978.1.

Chang, P., L. Zhang, R. Saravanan, D. J. Vimont, J. C. H. Chiang, L. Ji, H. Seidel, and M. K. Tippett, 2007: Pacific meridional mode and El Niño-Southern Oscillation. Geophys. Res. Lett., 34, L16608, https://doi.org/10.1029/2007GL030302.

Chiang, J. C. H., and D. J. Vimont, 2004: Analogous Pacific and Atlantic meridional modes of tropical atmosphere-ocean variability. J. Climate, 17, 4143-4158, https://doi.org/10.1175/JCLI4953.1.

Chiodi, A. M., and D. E. Harrison, 2017: Observed El Niño SSTA development and the effects of easterly and westerly wind events in 2014-2015. J. Climate, 30, 1505-1519, https://doi.org/ 10.1175/JCLI-D-16-0385.1.

Clement, A., P. DiNezio, and C. Deser, 2011: Rethinking the ocean's role in the Southern Oscillation. J. Climate, 24, 4056-4072, https://doi.org/10.1175/2011JCLI3973.1.

Compo, G. P., and Coauthors, 2011: The Twentieth Century Reanalysis Project. Quart. J. Roy. Meteor. Soc., 137, 1-28, https:// doi.org/10.1002/qj.776.

Dayan, H., J. Vialard, and T. Izumo, 2014: Does sea surface temperature outside the tropical Pacific contribute to enhanced
ENSO predictability? Climate Dyn., 43, 1311-1325, https:// doi.org/10.1007/s00382-013-1946-y.

Dee, D. P., and Coauthors, 2011: The ERA-Interim reanalysis: Configuration and performance of the data assimilation system. Quart. J. Roy. Meteor. Soc., 137, 553-597, https://doi.org/ 10.1002/qj.828.

Deser, C., and J. M. Wallace, 1990: Large-scale atmospheric circulation features of warm and cold episodes in the tropical Pacific. J. Climate, 3, 1254-1281, https://doi.org/10.1175/1520-0442 (1990)003<1254:LSACFO >2.0.CO;2.

- and Coauthors, 2012: ENSO and Pacific decadal variability in the Community Climate System Model version 4. J. Climate, 25, 2622-2651, https://doi.org/10.1175/JCLI-D-11-00301.1.

Di Lorenzo, E., G. Liguori, N. Schneider, J. C. Furtado, B. T. Anderson, and M. A. Alexander, 2015: ENSO and meridional modes: A null hypothesis for Pacific climate variability. Geophys. Res. Lett., 42, 9440-9448, https://doi.org/10.1002/ 2015 GL066281.

DiNezio, P. N., C. Deser, Y. Okumura, and A. Karspeck, 2017: Predictability of 2-year La Niña events in a coupled general circulation model. Climate Dyn., 49, 4237-4261, https://doi.org/ 10.1007/s00382-017-3575-3.

Ding, R., J. Li, and Y.-H. Tseng, 2015a: The impact of South Pacific extratropical forcing on ENSO and comparisons with the North Pacific. Climate Dyn., 44, 2017-2034, https://doi.org/ 10.1007/s00382-014-2303-5.

_ —_ and - 2015b: The Victoria mode in the North Pacific linking extratropical sea level pressure variations to ENSO. J. Geophys. Res. Atmos., 120, 27-45, https://doi.org/10.1002/ 2014JD022221.

,$--\longrightarrow$, C. Sun, and F. Xie, 2017: Joint impact of North and South Pacific extratropical atmospheric variability on the onset of ENSO events. J. Geophys. Res. Atmos., 122, 279-298, https://doi.org/10.1002/2016JD025502.

Elsner, J. B., and C. P. Schmertmann, 1994: Assessing forecast skill through cross validation. Wea. Forecasting, 9, 619-624, https://doi.org/10.1175/1520-0434(1994)009<0619:AFSTCV >2.0. $\mathrm{CO} ; 2$.

Furtado, J. C., E. Di Lorenzo, N. Schneider, and N. A. Bond, 2011: North Pacific decadal variability and climate change in the IPCC AR4 models. J. Climate, 24, 3049-3067, https://doi.org/ 10.1175/2010JCLI3584.1.

,-- B. T. Anderson, and N. Schneider, 2012: Linkages between the North Pacific Oscillation and central tropical Pacific SSTs at low frequencies. Climate Dyn., 39, 2833-2846, https:// doi.org/10.1007/s00382-011-1245-4.

Hasegawa, T., and K. Hanawa, 2003: Heat content variability related to ENSO events in the Pacific. J. Phys. Oceanogr., 33, 407-421, https://doi.org/10.1175/1520-0485(2003)033<0407:HCVRTE >2.0. $\mathrm{CO} ; 2$.

Hu, S., and A. V. Fedorov, 2016: Exceptionally strong easterly wind burst stalling El Niño of 2014. Proc. Natl. Acad. Sci. USA, 113, 2005-2010, https://doi.org/10.1073/pnas.1514182113.

Imada, Y., H. Tatebe, M. Watanabe, M. Ishii, and M. Kimoto, 2016: South Pacific influence on the termination of El Niño in 2014. Sci. Rep., 6, 30341, https://doi.org/10.1038/srep30341.

Jin, E. K., and Coauthors, 2008: Current status of ENSO prediction skill in coupled ocean-atmosphere models. Climate Dyn., 31, 647-664, https://doi.org/10.1007/s00382-008-0397-3.

Jin, F.-F., 1997: An equatorial ocean recharge paradigm for ENSO. Part I: Conceptual model. J. Atmos. Sci., 54, 811-829, https://doi.org/10.1175/1520-0469(1997)054<0811:AEORPF> 2.0.CO;2 
Kalnay, E., and Coauthors, 1996: The NCEP/NCAR 40-Year Reanalysis Project. Bull. Amer. Meteor. Soc., 77, 437-471, https://doi.org/10.1175/1520-0477(1996)077<0437:TNYRP> 2.0.CO;2.

Kao, H. and J. Yu, 2009: Contrasting eastern-Pacific and centralPacific Types of ENSO. J. Climate, 22, 615-632, https://doi.org/ 10.1175/2008JCLI2309.1.

Kara, A. B., P. A. Rochford, and H. E. Hurlburt, 2003: Mixed layer depth variability over the global ocean. J. Geophys. Res., 108, 3079, https://doi.org/10.1029/2000JC000736.

Kiladis, G. N., and K. C. Mo, 1999: Interannual and intraseasonal variability in the Southern Hemisphere. Meteorology of the Southern Hemisphere, Meteor. Monogr., No. 49, Amer. Meteor. Soc., 307-336.

Kim, S. T., and J.-Y. Yu, 2012: The two types of ENSO in CMIP5 models. Geophys. Res. Lett., 39, L11704, https://doi.org/10.1029/ 2012GL052006.

Kleeman, R., and A. M. Moore, 1997: A theory for the limitation of ENSO predictability due to stochastic atmospheric transients. J. Atmos. Sci., 54, 753-767, https://doi.org/10.1175/1520-0469 (1997)054<0753:ATFTLO >2.0.CO;2.

Kug, J., F. Jin, and S. An, 2009: Two types of El Niño events: Cold tongue El Niño and warm pool El Niño. J. Climate, 22, 1499-1515, https://doi.org/10.1175/2008JCLI2624.1.

Lai, W. C., M. Herzog, and H. F. Graf, 2017: ENSO forecasts near the spring predictability barrier and possible reasons for the recently reduced predictability. J. Climate, 31, 815-838, https:// doi.org/10.1175/JCLI-D-17-0180.1.

Landsea, C. W., and J. A. Knaff, 2000: How much skill was there in forecasting the very strong 1997-98 El Niño? Bull. Amer. Meteor. Soc., 81, 2107-2120, https://doi.org/10.1175/1520-0477 (2000)081<2107:HMSWTI>2.3.CO;2.

Larson, S., and B. Kirtman, 2014: The Pacific meridional mode as an ENSO precursor and predictor in the North American Multimodel Ensemble. J. Climate, 27, 7018-7032, https://doi.org/ 10.1175/JCLI-D-14-00055.1.

- , and —-, 2015: An alternate approach to ensemble ENSO forecast spread: Application to the 2014 forecast. Geophys. Res. Lett., 42, 9411-9415, https://doi.org/10.1002/ 2015 GL066173.

Latif, M., T. P. Barnett, M. A. Cane, M. Flügel, N. E. Graham, H. von Storch, J.-S. Xu, and S. E. Zebiak, 1994: A review of ENSO prediction studies. Climate Dyn., 9, 167-179, https:// doi.org/10.1007/BF00208250.

Liguori, G., and E. Di Lorenzo, 2018: Meridional modes and increasing Pacific decadal variability under anthropogenic forcing. Geophys. Res. Lett., 45, 983-991, https://doi.org/ 10.1002/2017GL076548.

Lin, C.-Y., J.-Y. Yu, and H.-H. Hsu, 2015: CMIP5model simulations of the Pacific meridional mode and its connection to the two types of ENSO. Int. J. Climatol., 35, 2352-2358, https:// doi.org/10.1002/joc.4130.

Linkin, M. E., and S. Nigam, 2008: The North Pacific oscillationwest Pacific teleconnection pattern: Mature-phase structure and winter impacts. J. Climate, 21, 1979-1997, https://doi.org/ 10.1175/2007JCLI2048.1.

Liu, Z., and M. Alexander, 2007: Atmospheric bridge, oceanic tunnel, and global climatic teleconnections. Rev. Geophys., 45, RG2005, https://doi.org/10.1029/2005RG000172.

Lübbecke, J. F., and M. J. McPhaden, 2014: Assessing the twentyfirst-century shift in ENSO variability in terms of the Bjerknes stability index. J. Climate, 27, 2577-2587, https://doi.org/ 10.1175/JCLI-D-13-00438.1.
McPhaden, M. J., 2003: Tropical Pacific Ocean heat content variations and ENSO persistence barriers. Geophys. Res. Lett., 30, 1480, https://doi.org/10.1029/2003GL016872.

Meehl, G. A., H. Loon, and J. M. Arblaster, 2017: The role of the Southern Hemisphere semiannual oscillation in the development of a precursor to central and eastern Pacific Southern Oscillation warm events. Geophys. Res. Lett., 44, 6959-6965, https://doi.org/10.1002/2017GL073832.

Meinen, C. S., and M. J. McPhaden, 2000: Observations of warm water volume changes in the equatorial Pacific and their relationship to El Niño and La Niña. J. Climate, 13, 3551-3559, https://doi.org/10.1175/1520-0442(2000)013<3551:OOWWVC > 2.0.CO;2.

Min, Q., J. Su, R. Zhang, and X. Rong, 2015: What hindered the El Niño pattern in 2014? Geophys. Res. Lett., 42, 6762-6770, https://doi.org/10.1002/2015GL064899.

$\longrightarrow,-$, and -2017 : Impact of the South and North Pacific meridional modes on the El Niño-Southern Oscillation: Observational analysis and comparison. J. Climate, 30, 17051720, https://doi.org/10.1175/JCLI-D-16-0063.1.

Miyakoda, K., G. D. Hembree, R. F. Strickler, and I. Shulman, 1972: Cumulative results of extended forecast experiments I. Model performance for winter cases. Mon. Wea. Rev., 100, 836-855, https://doi.org/10.1175/1520-0493(1972)100<0836: CROEFE $>2.3 . \mathrm{CO} ; 2$.

North, G. R., T. L. Bell, R. F. Cahalan, and F. J. Moeng, 1982: Sampling errors in the estimation of empirical orthogonal functions. Mon. Wea. Rev., 110, 699-706, https://doi.org/ 10.1175/1520-0493(1982)110<0699:SEITEO > 2.0.CO;2.

Okumura, Y. M., 2013: Origins of tropical Pacific decadal variability: Role of stochastic atmospheric forcing from the South Pacific. J. Climate, 26, 9791-9796, https://doi.org/10.1175/ JCLI-D-13-00448.1.

Penland, C., and P. D. Sardeshmukh, 1995: The optimal growth of tropical sea surface temperature anomalies. J. Climate, $\mathbf{8}$, 1999-2024, https://doi.org/10.1175/1520-0442(1995)008<1999: TOGOTS $>2.0 . \mathrm{CO} ; 2$.

Poli, P., and Coauthors, 2016: ERA-20C: An atmospheric reanalysis of the twentieth century. J. Climate, 29, 4083-4097, https://doi.org/10.1175/JCLI-D-15-0556.1.

Rayner, N. A., D. E. Parker, E. B. Horton, C. K. Folland, L. V. Alexander, D. P. Rowell, E. C. Kent, and A. Kaplan, 2003: Global analyses of sea surface temperature, sea ice, and night marine air temperature since the late nineteenth century. J. Geophys. Res. 108, 4407, https://doi.org/10.1029/2002JD002670.

Rogers, J. C., 1981: The North Pacific Oscillation. J. Climatol., 1, 39-57, https://doi.org/10.1002/joc.3370010106.

Smith, T. M., R. W. Reynolds, T. C. Peterson, and J. Lawrimore, 2008: Improvements to NOAA's historical merged land-ocean temperature analysis (1880-2006). J. Climate, 21, 2283-2296, https://doi.org/10.1175/2007JCLI2100.1.

Stuecker, M. F., 2018: Revisiting the Pacific meridional mode. Sci. Rep., 8, 3216, https://doi.org/10.1038/s41598-018-21537-0.

Su, J., B. Xiang, B. Wang, and T. Li, 2014: Abrupt termination of the 2012 Pacific warming and its implication on ENSO prediction. Geophys. Res. Lett., 41, 9058-9064, https://doi.org/ 10.1002/2014GL062380.

Suarez, M. J., and P. S. Schopf, 1988: A delayed action oscillator for ENSO. J. Atmos. Sci., 45, 3283-3287, https://doi.org/10.1175/ 1520-0469(1988)045<3283:ADAOFE > 2.0.CO;2.

Taylor, K. E., R. J. Stouffer, and G. A. Meehl, 2012: An overview of CMIP5 and the experiment design. Bull. Amer. Meteor. Soc., 93, 485-498, https://doi.org/10.1175/BAMS-D-11-00094.1. 
Thomas, E. E., and D. J. Vimont, 2016: Modeling the mechanisms of linear and nonlinear ENSO responses to the Pacific meridional mode. J. Climate, 29, 8745-8761, https://doi.org/ 10.1175/JCLI-D-16-0090.1.

Torrence, C., and G. P. Compo, 1998: A practical guide to wavelet analysis. Bull. Amer. Meteor. Soc., 79, 61-78, https://doi.org/ 10.1175/1520-0477(1998)079<0061:APGTWA > 2.0.CO;2.

Trenberth, K. E., and L. Smith, 2009: Variations in the threedimensional structure of the atmospheric circulation with different flavors of El Niño. J. Climate, 22, 2978-2991, https:// doi.org/10.1175/2008JCLI2691.1.

van Loon, H. and D. J. Shea, 1985: The Southern Oscillation. Part IV: The precursors south of $15^{\circ} \mathrm{S}$ to the extremes of the oscillation. Mon. Wea. Rev., 113, 2063-2074, https://doi.org/ 10.1175/1520-0493(1985)113<2063:TSOPIT>2.0.CO;2.

Vimont, D. J., D. S. Battisti, and A. C. Hirst, 2001: Footprinting: A seasonal connection between the tropics and mid-latitudes. Geophys. Res. Lett., 28, 3923-3926, https://doi.org/10.1029/2001GL013435.

_ J. M. Wallace, and S. Battisti, 2003a: The seasonal footprinting mechanism in the CSIRO general circulation models. J. Climate, 16, 2653-2667, https://doi.org/10.1175/1520-0442(2003)016<2653: TSFMIT $>2.0 . \mathrm{CO} ; 2$.

,$- \ldots$, and $-2003 \mathrm{~b}$ : The seasonal footprinting mechanism in the Pacific: Implications for ENSO. J. Climate, 16, 2668-2675, https://doi.org/10.1175/1520-0442(2003)016<2668:TSFMIT> 2.0.CO;2.

- M. Alexander, and A. Fontaine, 2009: Midlatitude excitation of tropical variability in the Pacific: The role of thermodynamic coupling and seasonality. J. Climate, 22, 518-534, https://doi.org/ 10.1175/2008JCLI2220.1.

, and M. Newman, 2014: Optimal growth of central and East Pacific ENSO events. Geophys. Res. Lett., 41, 4027-4034, https://doi.org/10.1002/2014GL059997.

Xie, S.-P., and S. G. H. Philander, 1994: A coupled ocean-atmosphere model of relevance to the ITCZ in the eastern Pacific. Tellus, 46, 340-350, https://doi.org/10.3402/tellusa.v46i4.15484.

You, Y., and J. C. Furtado, 2017: The role of South Pacific atmospheric variability in the development of different types of ENSO. Geophys. Res. Lett., 44, 7438-7446, https://doi.org/ 10.1002/2017GL073475.

Yu, J.-Y., and S. T. Kim, 2011: Relationships between extratropical sea level pressure variations and the central Pacific and eastern Pacific types of ENSO. J. Climate, 24, 708-720, https://doi.org/ 10.1175/2010JCLI3688.1.

Zebiak, S. E., and M. A. Cane, 1987: A model El NiñoSouthern Oscillation. Mon. Wea. Rev., 115, 2262-2278, https://doi.org/10.1175/1520-0493(1987)115<2262:AMENO>2.0. $\mathrm{CO} ; 2$.

Zhang, H., A. Clement, and P. DiNezio, 2014a: The South Pacific meridional mode: A mechanism for ENSO-like variability. J. Climate, 27, 769-783, https://doi.org/10.1175/ JCLI-D-13-00082.1.

, C. Deser, A. Clement, and R. Tomas, 2014b: Equatorial signatures of the Pacific meridional modes: Dependence on mean climate state. Geophys. Res. Lett., 41, 568-574, https:// doi.org/10.1002/2013GL058842. 